\author{
UNIVERSIDADE DE SÃO PAULO \\ ESCOLA DE ENGENHARIA DE SÃO CARLOS
}

Matheus de Sena Dall'Agnol

\title{
IN THE MULTITUDE OF WORDS, SIN IS NOT LACKING: AN ANALYSIS OF CODES OF ETHICS ACROSS FORTUNE 500 COMPANIES
}

São Carlos 

Matheus de Sena Dall'Agnol

\section{IN THE MULTITUDE OF WORDS, SIN IS NOT LACKING: AN ANALYSIS OF CODES OF ETHICS ACROSS FORTUNE 500 COMPANIES}

Dissertação apresentada à Escola de Engenharia de São Carlos da Universidade de São Paulo, para obtenção do título de Mestre em Ciências - Programa de Pós-Graduação em Engenharia de Produção.

Área de concentração: Economia, Organizações e Gestão do Conhecimento

Supervisor: Prof. Dr. Luiz Ricardo Kabbach de Castro

\section{VERSÃO CORRIGIDA}

\section{São Carlos}



AUTORIZO A REPRODUÇÃO TOTAL OU PARCIAL DESTE TRABALHO POR QUALQUER MEIO CONVENCIONAL OU ELETRÔNICO, PARA FINS DE ESTUDO E PESQUISA, DESDE QUE CITADA A FONTE.

Ficha catalográfica elaborada pela Biblioteca Prof. Dr. Sérgio Rodrigues Fontes da EESC/USP com os dados inseridos pelo(a) autor(a).

Dall'Agnol, Matheus

D144i IN THE MULTITUDE OF WORDS, SIN IS NOT LACKING: AN ANALYSIS OF CODES OF ETHICS ACROSS FORTUNE 500 COMPANIES / Matheus Dall'Agnol; orientador Luiz Ricardo Kabbach de Castro. São Carlos, 2021.

Dissertação (Mestrado) - Programa de Pós-Graduação em Engenharia de Produção e Área de Concentração em Economia, Organizações e Gestão do Conhecimento -- Escola de Engenharia de São Carlos da Universidade de São Paulo, 2021.

1. Behavioral. 2. Legal. 3. Code of Ethics. 4. Code of Conduct. 5. Business Code. I. Título.

Eduardo Graziosi Silva - CRB - 8/8907 



\section{FOLHA DE JULGAMENTO}

Candidato: Engenheiro MATHEUS DE SENA DALL'AGNOL.

Título da dissertação: "Na multidão de palavras, não faltam pecados: uma análise de códigos de ética entre empresas da Fortune 500".

Data da defesa: 23.02 .2021

\section{Comissão Julgadora}

Prof. Dr. Luiz Ricardo Kabbach de Castro

(Orientador)

(Warrington College of Business/EUA)

Profa. Dra. Dulce María Redín Goñi

(Universidade de Navarra/UNAV)

Prof. Till Talaulicar

(Universität Erfurt/Uni ERFURT)

\section{Resultado}

Aprovado

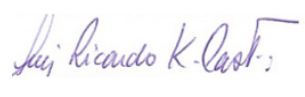

Aprovado

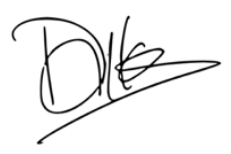

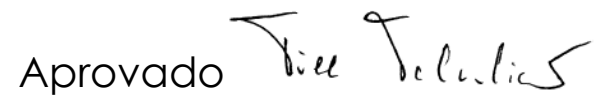

Coordenadora do Programa de Pós-Graduação em Engenharia de Produção:

Profa. Dra. Janaina Mascarenhas Hornos da Costa

Presidente da Comissão de Pós-Graduação:

Prof. Titular Murilo Araujo Romero 

We dedicate this work to all academic-practitioners that go beyond the conventional wisdom. We praise those that have no fear of uncharted territories. 



\section{ACKNOWLEDGEMENTS}

We want to thank all of those who, directly or indirectly, made this work go from a small and faint idea inside the authors' imagination to a full, robust, and comprehensive statement on ethical decision-making in organizations. The amount of progress in such a short period is a collective construction rather than an individual success from any of the authors.

We are keenly aware that many barriers are still to come, as our journey is only beginning. However, past successes are usually an excellent predictor of future victories whenever hard work, friendship, and open communication are present. To date, no one was able to convince us otherwise. 

"Economists think about what people ought to do.

Psychologists watch what they actually do." 



\section{ABSTRACT}

\section{DALL'AGNOL, M.S IN THE MULTITUDE OF WORDS, SIN IS NOT}

LACKING: AN ANALYSIS OF CODES OF ETHICS ACROSS FORTUNE 500 COMPANIES. 2021. 76p. Dissertação (Mestrado) - Escola de Engenharia de São Carlos, Universidade de São Paulo, São Carlos, 2021.

Despite millions of dollars being deployed to few studies have been able to effectively address and measure the effectiveness of codes of ethics in reducing misbehavior. In this article, we propose to evaluate what information codes can highlight in terms of deeper ethical structures of organizations. We suggest that codes of ethics can be separated into two different contents: a legal approach, based on rational decision-making and mainly focused on the institutional legal framework, and a behavioral approach takes onboard insights from the behavioral ethics literature. To evaluate both the codes' structure and development empirically, we decided to use Fortune 500's public companies dataset.

Our results show that, via cluster analysis, three main code categories emerged: legalistic codes, behavioral codes, and paper codes - which have low proportions of both legal and behavioral content, . Also, by evaluating the relationship between code effectiveness and content, we found that companies with higher behavioral content had a better compliance effectiveness system when measured as risk behavior. However, behavioral content fared worse when measured against the risk of class action litigations.

We believe that our results may shed light on how to improve compliance policies better and how to build guidelines that effectively consider how key stakeholders effectively make ethical decisions. By structuring compliance guidelines that take into consideration the particularities of each organization, we will be one step closer to foster and create truly ethical organizations.

Keywords: Behavioral. Legal. Code of Ethics. Code of Conduct. Business Code. Compliance. Legalistic Codes. Hybrid Codes. Organizations. Decision-Making. Ethics. 



\title{
RESUMO
}

\author{
DALL'AGNOL, M.S NA MULTIDÃO DE PALAVRAS, NÃO FALTAM \\ PECADOS: UMA ANÁLISE DO CÓDIGO DE ÉTICA ENTRE \\ EMPRESAS DA FORTUNE 500. 2021. 76p. Dissertação (Mestrado) - Escola de \\ Engenharia de São Carlos, Universidade de São Paulo, São Carlos, 2021.
}

Ainda que bilhões de dólares sejam gastos todo ano com as políticas de compliance, poucos estudos foram capazes de efetivamente medir o efeito de tamanho dispêndio na redução de conduta inapropriada. Neste artigo, propomos analisar os códigos de ética para avaliarmos quais informações presentes no código podem ser investigadas de maneira sistemática.Argumentamos que os códigos de ética podem ser separados em duas grandes abordagens: códigos com abordagens legalistas, baseadas na tomada de decisão racional dos indivíduos e focadas no framework institucional jurídico. Por outro lado, abordagens comportamentais, baseada na ética comportamental, foca em características pessoais e ambientais que podem reduzir a conduta anti-ética, indo além da abordagem racional clássica. Para avaliarmos empiricamente nossas proposições teóricas, nós utilizamos a base de dados de corporações públicas da Fortune 500.

A partir dos dados, encontramos que os mesmos suportam nossas proposições teóricas iniciais: por meio de análise de agrupamentos, descobrimos três principais categorias de códigos: códigos "de fachada", códigos legalistas e códigos comportamentais. Ademais, verificarmos se há algum tipo de diferença na efetividade do sistema de compliance dependendo do conteúdo de cada código. Foi encontrado que uma proporção maior de conteúdos comportamentais está correlacionado de forma significativa com uma menor probabilidade de se ocorrerem eventos de risco. Também, uma proporção maior de conteúdos legalistas também está correlacionada com uma probabilidade maior de ocorrer esses eventos de risco. Quando utilizamos como medida de efetividade do sistema de compliance variáveis de resultado como litígios, os resultados apontam para um resultado pior de códigos comportamentais quando correlacionados com o risco de litígios.

Acreditamos que os resultados encontrados neste artigo podem auxiliar na construção de políticas de compliance que efetivamente considerem como pessoas-chave para a empresa como os funcionários - realmente tomam decisões éticas. Ao considerar as particularidades de cada organização e desenvolver mecanismos específicos para tais, estaremos mais próximos de criamos organizações realmente éticas.

Palavras-chave: Comportamental. Legal. Código de Ética. Código de Conduta. Compliance. Códigos Legalistas. Códigos Híbridos. Tomada de Decisão. Ética. 



\section{LIST OF FIGURES}

Figure 1 - Theoretical Clusters . . . . . . . . . . . . . . 36

Figure 2 - 2017 Fortune 500 Breakdown per Sector . . . . . . . . . . . . . 39

Figure 3 - Relationship Between Code Content, Misbehavior and Litigation Outcomes 50

Figure 4 - Theoretical Clusters Concept . . . . . . . . . . . . . 54

Figure 5 - Plots of Z-Score and Relative Measure Clusters . . . . . . . . . . . . 55

Figure 6 - Plots of Alternative Distance Variables Clusters . . . . . . . . . . . 55

Figure 7 - Plots of Relative Measure and Alternative Distance Variables Clusters . 56

Figure 8 - Plots of Z-Score and Alternative Distance Variables Clusters . . . . . . 57

Figure 9 - Plots of Raw Percentage and Alternative Distance Variables Clusters . 57

Figure 10 - Predictive Margins Plot of Class Action Likelihood . . . . . . . . . . . 64

Figure 11 - Relation Between Total Outcomes and Legal Outcomes . . . . . . . . . 68 



\section{LIST OF TABLES}

Table 1 - Code Adoption: Studies from 1980 to 2014 . . . . . . . . . . . . . . . . 30

Table 2 - Codes' Number of Pages and Words per Sector . . . . . . . . . . . . . . 41

Table 3 - ESG Issues Breakdown per ESG Issue Type . . . . . . . . . . . . . . . 42

Table 4 - ESG Issues Breakdown per ESG category . . . . . . . . . . . . . . . 42

Table 5 - Violations Breakdown per UNGC Principle . . . . . . . . . . . . . 43

Table 6 - Violations Breakdown per UNGC Category . . . . . . . . . . . . . . 43

Table 7 - ESG Issues Breakdown per Sector and per Severity . . . . . . . . . . . . 44

Table 8 - UNGC Violations Breakdown per Sector and per Severity . . . . . . . 44

Table 9 - Class Action Fillings Distributed by Industry Sector . . . . . . . . . . . 45

Table 10 - Sample of Words into Legal and Behavioral Dictionaries . . . . . . . . . 46

Table 11 - Legal Perspective: Average Number of Words and Percentages . . . . . . 47

Table 12 - Behavioral Perspective: Average Number of Words and Percentages . . . 47

Table 13 - Duda-Hart and Calinski Harabasz Stopping Rules . . . . . . . . . . . . 53

Table 14 - Zero-Inflated Model with High Severity ESG Issues . . . . . . . . . . . . 58

Table 15 - Zero-Inflated Model with Medium Severity ESG Issues . . . . . . . . . . 59

Table 16 - Zero-Inflated Model with Low Severity ESG Issues . . . . . . . . . . . . 59

Table 17 - Zero-Inflated Model with Medium Severity UNGC Violations . . . . . . 61

Table 18 - Zero-Inflated Model with Low Severity UNGC Violations . . . . . . . . 61

Table 19 - OLS Regression Results Without Delaware Dummy . . . . . . . . . . . 62

Table 20 - OLS Regression Results With Delaware Dummy . . . . . . . . . . . 63 



\section{LIST OF ABBREVIATIONS AND ACRONYMS}

\begin{tabular}{ll} 
APA & American Psychology Association \\
AIC & Akaike Information Criterion \\
BIC & Bayesian Information Criterion \\
CH & Calinski-Harabasz Stopping Rule \\
CH & Duda-Hart Stopping Rule \\
EHS & Environment, Health and Safety \\
ESG & Environmental, Social and Corporate Governance \\
FCPA & Foreign Corrupt Practices Act \\
GLM & Generalized Linear Model \\
OLS & Ordinary Least Squares \\
SCAC & Securities Class Action Clearinghouse \\
SEC & Securities and Exchange Comission \\
SOX & Sarbanes-Oxley Act \\
UNGC & United Nations Global Compact \\
UNCTAD & United Nations Conference on Trade and Developmen \\
ZIN & Zero-Inflated Negative Binomial Models \\
\hline
\end{tabular}





\section{CONTENTS}

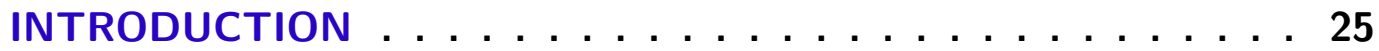

2

LITERATURE REVIEW AND HYPOTHESES DEVELOPMENT . . 29

2.1 PREVALENCE OF CODES IN ORGANIZATIONS 29

2.2 CODE EFFECTIVENESS 31

2.3 CODE CATEGORIZATION 31

2.3.1

Legal Perspective 33

2.3.2 Behavioral Perspective 34 A New Categorization of Codes: Legal and Behavior Perspectives . . . . . . 36 HYPOTHESES DEVELOPMENT 37 METHODS ........................... 39

3.1 SAMPLE . 39

Risk of Misconduct 41

3.3.1 Cluster Analysis . . . . . . . . . . . . . . . . . . . . . . 48

3.3.2 Regression Analysis . . . . . . . . . . . . . . . . . 49

3.3.2.1 Risk of Misbehavior . . . . . . . . . . . . . . . . . . . . 49

3.3.2.2 Risk of Litigation . . . . . . . . . . . . . . . . . . . . 50

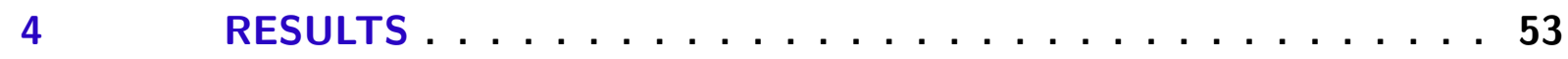

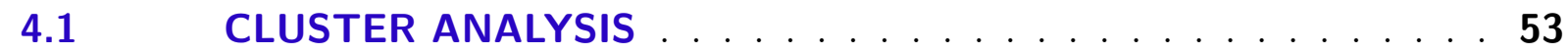

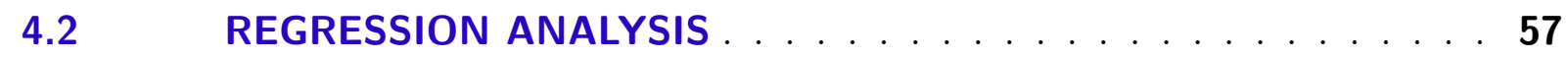

4.2.1 Risk of Misbehavior . . . . . . . . . . . . . . . . 57

4.2.2 Risk of Litigation . . . . . . . . . . . . . . . . . 61

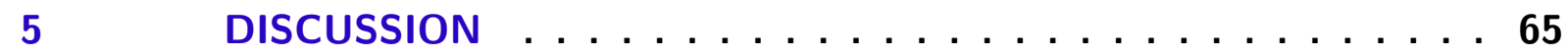

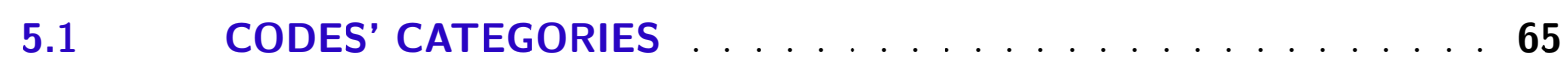

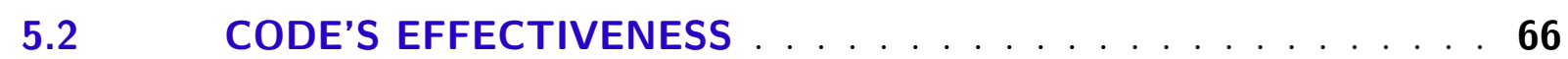

$5.2 .1 \quad$ Risk of Misbehavior . . . . . . . . . . . . . . . . 66

5.2 .2 Risk of Litigation . . . . . . . . . . . . . . . . . . 67

5.3 WHY SHOULD WE CARE ABOUT CODES? . . . . . . . . 67 
5.4

FUTURE STUDIES

6

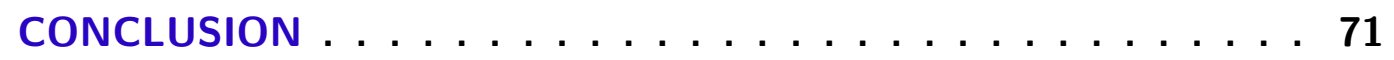

BIBLIOGRAPHY

73 


\section{INTRODUCTION}

At 9 a.m. on April 24, 2013, Rana Plaza, a building complex in Bangladesh's capital, Dhaka, collapsed, killing 1,135 clothing workers and injuring over 2500 more (CHOWDHURY, 2017). On the illegally constructed fifth and seventh floors on the building, New Wave, a subcontractor of Canada's largest retailer - Loblaws - operated. As the majority of western companies, Loblaws stated to have clear compliance guidelines, which included a supplier code of conduct to be followed by every subcontractor of the Canadian corporation, including a requirement for suppliers to maintain a safe and healthy workplace (DOOREY, 2018).

Rana Plaza's tragedy, more than a humanitarian one, also highlights the structure and purposefulness of codes of ethics and conduct in many enterprises. In a lawsuit (i.e., a class action) filed by the victims claiming Loblaws' negligence on the case, Loblaws downplayed its compliance efforts, stating that the code "only gives the Loblaws Defendants the right to rescind their orders if Pearl Global [the main contractor, Loblaws' supplier] does not comply with their ethical guidelines. It does not purport to give the Loblaws Defendants any right to control the actions of New Wave [the subcontractor at Rana Plaza], which is not even a party to the agreement" (DOOREY, 2018, p.41).

Given what was at stake - the victims claimed $\$ 1.85$ billion in general damages, $\$ 150$ million in punitive damages, and other remedies -, Loblaws reverted to a legal and formal interpretation of its internal compliance policies, conceding to critics of formal ethical structures a seminal case of ethical codes being used as a legal and public relations tool, deployed at best to deflect criticism and protect reputational and legal liabilities instead of being an asset to be used to promote better corporate practices and organizational change (DOOREY, 2018). In 2017, Justice Perell, from Ontario's Supreme Court, dismissed the case on the basis that it was direct and obvious that the claims were not legally viable ${ }^{1}$.

This case raises the following question, are codes of ethics (and conduct) developed to protect the firms from legal litigation or, otherwise, to develop ethical behavior?

The code of ethics (henceforth, code) - "a policy document that defines the responsibilities of the corporation towards its stakeholders and the conduct the corporation expects of its employees" (KAPTEIN, 2004, p. 15) - sets the basis of a corporate compliance system. Therefore, codes' effectiveness in addressing ethical organizational behavior has been a recurrent theme in business ethics and corporate governance literature. Indeed, efforts to link the presence of a corporate code with strong ethical standards are ubiquitous, but yet the results are inconclusive or contradictory (FORD; RICHARDSON, 1994; LOE;

1 Das v. George Weston Limited, 2017 ONSC 4129 
FERRELL; MANSFIELD, 2000; CRAFT, 2013; O'FALLON; BUTTERFIELD, 2005; LEHNERT; PARK; SINGH, 2015).

We believe that the conflicting results on the effectiveness of codes have two main drivers. From a theoretical perspective, there is not enough discussion regarding the code's inner assumptions, especially related to how ethical decision-making is understood and what ought to be the right approach to create an ethical environment. From an empirical perspective, the differences across codes and the absence of an accepted categorization of them may lead to comparability concerns and, therefore, to inconclusive evidence on the effects of codes on organizational behavior.

In this study, we aim to address these two points. From a theoretical standpoint, we propose two alternative and complementary theoretical perspectives for analyzing the code's structure. First, and aligned with the mainstream literature in corporate compliance (TENBRUNSEL; SMITH-CROWE; UMPHRESS, 2003; PAINE, 1994; TREVINO; YOUNGBLOOD, 1990; WEAVER, 1993), a legal perspective ${ }^{2}$, which assumes the individual as rational decision-makers who perform a cost-benefit analysis to solve ethical dilemmas (SOLTES, 2016; BECKER, 1968). Second, a behavioral perspective that includes conceptual constructs from behavioral ethics that examine individuals' misbehavior with a different lens, including factors that are not prominent in the cost-benefit analysis approach, such as social ties, group behavior, leadership mimicking, moral awareness, and organizational micro-cultures (BAZERMAN; GINO, 2012).

With these two conceptual perspectives in mind, we aim to address the following overarching questions: (a) How prevalent are the legal and behavioral perspectives in defining the structure and writings of an organization's code of ethics?, and (b) What is, if any, the relationship between code's legal and behavior structure on ethical behavior of firms?

From an empirical standpoint, to answer the first question, we perform a content analysis (CALDERÓN; FERRERO; REDIN, 2012; STOHL; STOHL; POPOVA, 2009; SCHWARTZ, 2004) to measure the legal and behavior structure of corporate codes from Fortune 500 companies. To do so, we rely on external dictionaries, the American Psychological Association (APA) glossary, to capture the behavior construct and the legal lexicon of the most frequent words used in the U.S. courts to grasp the legal construct. With these two measures, we examine whether our underlying theoretical perspectives exist by applying a cluster analysis that is an appropriate method to explore interrelated dimensions for the discovery of insightful conceptualizations(GRIMMER; KING, 2011).

2 We follow Haugh (2017) discussion on criminal compliance systems when defining the term "legal", which we think suits well to explain our phenomenon. According to the author, many compliance systems use the same approach as criminal law does, including prescriptive and corrective measures. 
Once we understand whether and how codes' structure define different categories, we analyze the effect of code's structure on firms' ethical behavior. To test the codes' effectiveness, we gather companies' reported issues on environmental, social, and governance, as defined by the RepRisk ESG database ${ }^{3}$. Also, we evaluate possible outcomes linked with compliance effectiveness using class action litigations from the Stanford Law School Litigation Database.

Our results show that different clusters exist when evaluating behavioral and legal content. From a priori theoretical clusters, our analysis identified three types of codes: paper, behavioral and legal codes. Behavioral codes comprise the most significant proportion of our sample, which is aligned with empirical evidence that firms are transitioning from a shareholder perspective to a more broader stakeholder consideration (BAKKER; RASCHE; PONTE, 2019; STOHL; STOHL; POPOVA, 2009). Thus, even though legal implications are considered (as there is not such a thing as pure legal or behavior codes), there seems to be a pattern in the codes aiming at influencing the ethical conduct of organizational agents.

Moving to the analysis of the effectiveness of codes based on its behavioral and legal content, we find that behavioral orientation of codes reduces the likelihood of environmental, social, and governance (ESG) issues. In contrast, legal orientation of codes increases the likelihood of ESG issues. We also find that class actions are more likely to appear in behavior than legal-oriented codes.

Our findings have several implications for business ethics and governance. First, we provide a new and meaningful way to categorize corporate codes of ethics that are grounded on theory and empirically valid. The new categories of codes also may help to explain prior conflicting results on the effectiveness of codes that implicitly assumed that codes are homogeneous. Second, by taking a complementarity approach to evaluate whether there are optimal structures that balance legal and behavior design to reduce corporate misbehavior, we shed new light not only on the nature of codes but also on the effect of codes on the risk of misconduct and the outcomes of them.

Finally, companies are spending considerable sums on compliance programs - in the United States alone, firms spend, on average $\$ 3.5$ million (SOLTES, 2017), figures that can surge up to hundreds of millions of dollars with thousands of employees fully dedicated to compliance initiatives, which calls for an analysis of what works and what does not. Therefore, by teasing out the key code's structures that matter most to ethical behavior, we inform how organizations can improve their compliance mechanisms to allocate resources into practices that help to improve ethical behavior.

This article is organized as follows. First, we review the literature of corporate

3 For more information on the RepRisk database, please check the RepRisk website at $<$ www. reprisk.com> 
codes of ethics and its implications to ethical behavior. Then, we discuss how behavioral ethics can handle the interface between individual ethical decision-making and organizational measures to curb misconduct. In section 2, develop our hypotheses regarding the code's different structure and categorization, and their effectiveness in reducing corporate misconduct. Section 3 describes our empirical design. Lastly, in the remaining two sections, we discuss our results and their main implications and conclude highlighting future avenues of research. 


\section{LITERATURE REVIEW AND HYPOTHESES DEVELOPMENT}

\subsection{PREVALENCE OF CODES IN ORGANIZATIONS}

Many of the changes in codes, throughout the decades, have been designed to cope with regulatory changes that required code readjustments. For example, the emergence of the Foreign Corrupt Practices Act (FCPA) of 1979 and the U.S. Sentencing Commissions Federal Guidelines for Sentencing Organizations in 1991, setting standards for effective programs aimed at reducing violations of law, have triggered a systemic update of codes (CRESSEY; MOORE, 1983; WARREN, 1993; PAINE, 1994). Even though much of the code restructuring efforts has been a reactive response to changes in the institutional environment, one cannot rule out the strength of stakeholder demands in compliance programs that may overreach the legal environment (SOLTES, 2017).

Weaver (1993) was one of the first to systematically assess whether code adoption was becoming a trend within the business environment. According to this study, code adoption varies dramatically based on size, revenue, headquarters location, and industrial segment. Indeed, code adoption ranged from $24 \%$ up to $93 \%$. In the same vein, Weaver, Treviño \& Cochran (1999) performed a corporate survey where the adoption of codes or other similar compliance mechanisms were reported by almost $78 \%$ of their sample, which comprised Fortune 500 industrial and service corporations. The results were in line with (WEAVER, 1993) findings, suggesting that more prominent corporations had a higher level of code adoption than smaller firms.

Kaptein (2004) meta-analysis on code adoption from 1999 up to 2003 (and complementing his research) showed that adoption rates vary considerably, ranging from $37 \%$ up to 78\%. Also, Calderón-Cuadrado et al. (2009) examines a sample of 150 top corporations from the United Nations Conference on Trade and Development (UNCTAD) and find that $67 \%$ of firms from their study disclose a code in their public media (e.g., websites).

By focusing on the most admired companies in the world, Calderón, Ferrero \& Redin (2012) report that $92 \%$ of the 50 most admired corporations had adopted codes. The fact that a higher-than-average code adoption from the most admired organizations is an indication that code adoption is positively correlated with higher satisfaction and admiration. More recently, Kaptein (2014), in his study together with the consulting company KPMG, analyzed a sample of a broad spectrum of multinational firms - especially from Asia - and found that $76 \%$ of firms developed their codes in the last decade.

From the above studies, one can assume that code adoption is increasing and becoming a standard across firms and countries, particularly large corporations. In Table 1 , we present a summary of the literature and its findings regarding code adoption. 


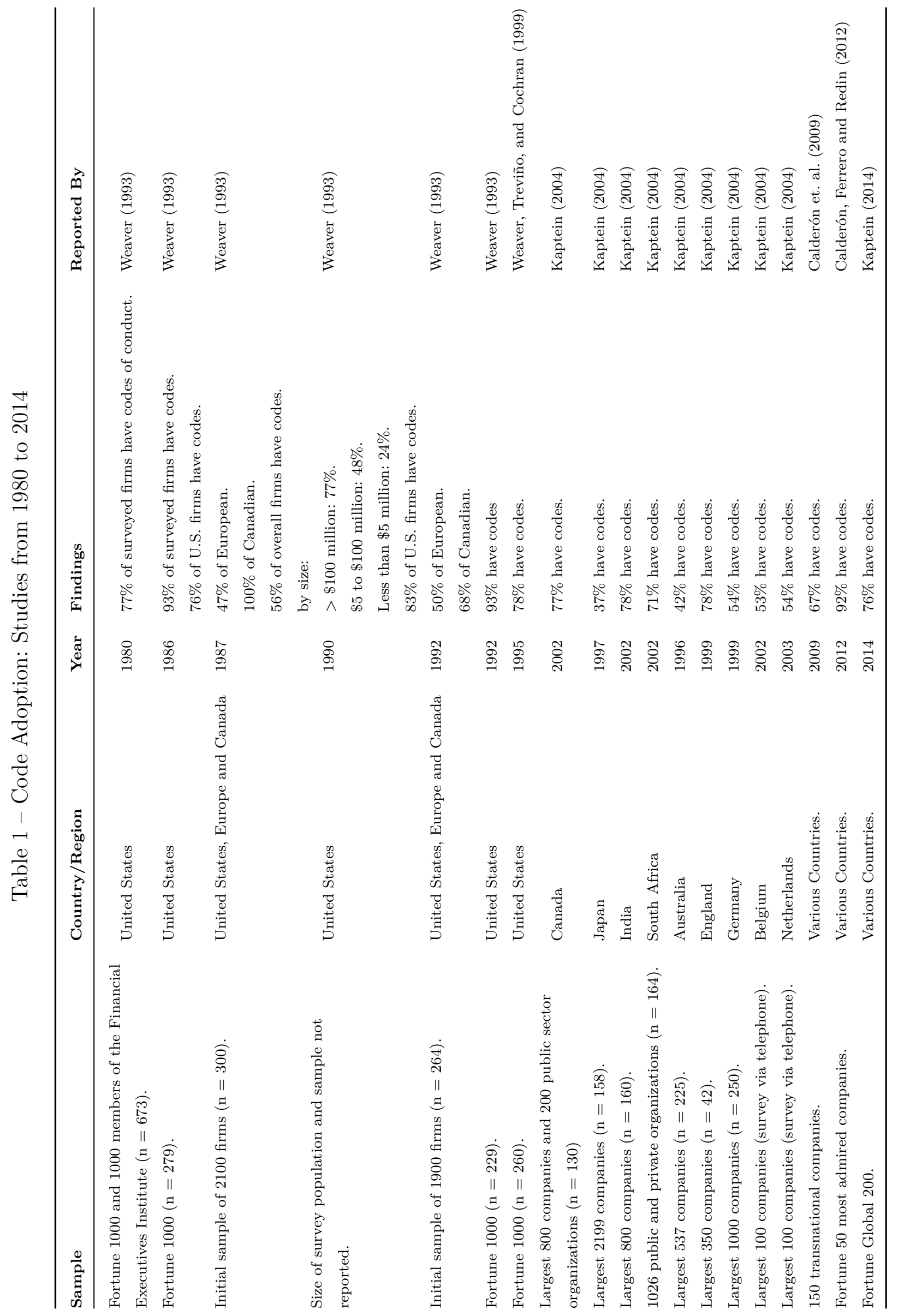




\subsection{CODE EFFECTIVENESS}

The empirical study of the effectiveness of codes in decreasing unethical conduct and increasing ethical behavior has been prevalent since the first comprehensive review of ethical decision-making was released (FORD; RICHARDSON, 1994). Much of the evidence points to the positive effects of codes on ethical decision-making, albeit the considerable number of studies that did not find any significant developments. In general, the odds favor a positive contribution, but the mixed results are worrisome (LEHNERT; PARK; SINGH, 2015; O'FALLON; BUTTERFIELD, 2005; LOE; FERRELL; MANSFIELD, 2000; FORD; RICHARDSON, 1994; CRAFT, 2013).

Efforts to explain the mixed results are abundant (KAPTEIN; SCHWARTZ, 2008). In a follow-up study, Kaptein (2011) highlighted the fact that isolated analyses are often not able to take into account other surrounding factors that may dictate the effectiveness or not of a code's statements. Therefore, from the discussions mentioned above, it is clear that evaluating a code's significance is far from consensual, and the problem of effectiveness lies deep within the compliance literature in general (SOLTES, 2017).

There have been few discussions regarding how human behavior is understood and translated into a code's settings. According to Soltes (2017), this lack of depth on the matter exacerbates the problem of not having reliable and robust measures for evaluating a code's effectiveness in tackling organizational misbehavior. To measure the effectiveness of codes, an analysis of how individual decision-making is implicitly modeled is fundamentally vital as both a theoretical and empirical construct.

The review on the effectiveness of codes is clear: despite the increasing efforts in the last 25 years to increase the size and complexity of compliance programs, there is no consensual way of analyzing whether this investment is being directed into fruitful measures (HAUGH, 2017). The current tools deployed by regulators in the United States - and followed elsewhere - are purposefully vague, such as attendance rates for training sessions as a measure of effectiveness. As opposed to other corporate departments, such as marketing, compliance falls short of a solid framework to assess the return on investment from such expenditures (SOLTES, 2017).

\subsection{CODE CATEGORIZATION}

One of the early contributions to a systematic analysis of a code's content and objectives was made by Cressey \& Moore (1983), in which four primary categories, ranging from policy procedures up to compliance explanations, were identified. Despite the abovementioned authors' pioneering efforts, not much has been said about the main stakeholders targeted by the code's structure, nor the code's actions beyond the legal realm. One exception to the rule is the work of Stohl, Stohl \& Popova (2009), where the authors 
claim that codes can be categorized in generations, ranging from inward-looking types up to broader scopes, which included external stakeholders (e.g., environment and society). While being compelling, Stohl, Stohl \& Popova (2009) limit their study to the theoretical underpinnings of code's structure, and therefore no empirical validation is examined.

To empirically validate Stohl et al. contributions, Calderón, Ferrero \& Redin (2012) extend this line of research by developing a content analysis of codes of the Most Admired Companies in the World. Drawing upon Stohl, Stohl \& Popova (2009) categorization, they found that much of a code's content remained in first- and second-generation realms, despite the efforts made towards disentangling a company's code perspective from its shareholders and employees only. The companies' codes resembled more codes of conduct than broader codes of Corporate Social Responsibility, as a third-generation code would suggest.

It is equally important to mention Kaptein (2004) analysis of a code's structure, who split code structures across categories of stakeholder statutes, values statements, and codes of conduct. Instead of using the Stohl, Stohl \& Popova (2009) internal/external approach, Kaptein (2004) arguments centered on the descriptive/prescriptive nature of the codes. While stakeholder statutes are mostly descriptive and inward-looking, codes of conduct had a much more prescriptive nature, maintaining their internal anchor perspective.

Codes can also be categorized according to their orientation: output-oriented, content-oriented, or transformation-oriented (BABRI; DAVIDSON; HELIN, 2019). The authors' findings are similar to those found on Forster, Loughran \& McDonald (2009): that value statements - or transformation-oriented codes according to (BABRI; DAVIDSON; HELIN, 2019) — are scant when compared to legal statements (or output-oriented and content-oriented ones). The general concept is to have codes that rely on impersonal and detached judicial objectives to the detriment of codes rooted in organizational behavior.

Although the business ethics literature provides different ways to categorize $\operatorname{codes}^{1}$ we believe that previous categorization efforts did not grasp the fundamentals of ethical decision-making among individuals and, therefore, may have little (if any) effect on how effective can be the codes to mitigate corporate misbehavior.

Internally or externally oriented, how companies model human decision-making is crucial for developing ethical mechanisms that support decision-making assumptions. Therefore, we propose two new conceptual constructs to categorize codes as follows: (1) legal perspective (henceforth, legal), which embeds rationality assumptions of economics (e.g., cost-benefit analysis), and (2) behavioral perspective (henceforth, behavioral), which is supported by the behavioral ethics literature.

1 For a brief discussion on other categorizations, please refer to Calderón, Ferrero \& Redin (2012). 


\subsubsection{Legal Perspective}

Legal codes embed into their decision-making mechanisms the standard approach to ethical decision-making as in Gary Becker's approach, summarized by the author in his 1993 Nobel laureate speech:

"I began to think about crime in the 1960 s after driving to Columbia University for an oral examination of a student in economic theory. I was late and had to decide quickly whether to put the car in a parking lot, or risk getting a ticket for parking illegally on the street. I calculated the likelihood of getting a ticket, the size of the penalty, and the cost of putting the car in a lot. [...] The frequency of their inspection of parked vehicles and the size of the penalty imposed on violators should depend on their estimates of the type of calculations potential violators like me would make." (BECKER, 1993, p.5)

Corporate codes, throughout its history of adoption, have been focused on legal and regulatory issues for better safeguarding the firm against actions from external threats (SCHWARTZ, 2005). Babri, Davidson \& Helin (2019), developing a metadata study on corporate codes, state that the primary roles of corporate codes is that of self-defense, and are heavily influenced by corporate legal departments. These legal codes are protectionist in nature and are centered on being prepared to face challenges against the firm than actions by the corporation itself. As Lere \& Gaumnitz (2003) conclude, there are scant references to ethics in codes and a more predominant focus on essential laws and compliance requirements.

With the emergence of a wider group of vocal stakeholders and efforts towards increasing the breadth of corporate codes' objective, one might believe that legal codes have diminished importance nowadays. However, Babri, Davidson \& Helin (2019) highlight that the significance of legal content on corporate codes remains a priority in most organizations, as there are underlying environmental factors that create a greater dependence on legal compliance. For instance, the Sarbanes-Oxley Act incentivized companies to be prescriptive and emphasize legal and regulatory aspects within the code (CANARY; JENNINGS, 2008). Singh (2006) also points out that mentions "legal responsibility" has increased significantly from 1992 to 2003, as well as an increase in code enforcement and compliance procedures.

Bondy, Matten \& Moon (2004) argues that legal-focused codes are punitive - that is, they use threats of sanctions for non-compliance behavior - and have a quasi-legal role inside organizations. They are generally used to not only be following the external regulatory environment but also to exert control in managerial behavior and ensure consistent operations across different branches, especially when dealing with multinational corporations. The notion of a standardized code across countries is another evidence of the 
importance of legal influence in code development (BABRI; DAVIDSON; HELIN, 2019). Legal precedence is key to court disputes and is used by legal departments when protecting the company's interest. Therefore, in legal codes, jurisprudence overrides concerns of originality (FORSTER; LOUGHRAN; MCDONALD, 2009).

The standardization and protectionist nature of codes have induced companies to develop codes that are similar among one another, creating an isomorphism of codes across different organizations. According to Holder-Webb \& Cohen (2012), which analyzed 75 US firms across five other industry sectors, there is a language and content convergence regarding code development, being a rational response to the emergence of new regulatory requirements. Notwithstanding the fact that US regulations aim at promoting code diversity, they have failed to induce corporate change and higher ethical standards. The same isomorphism behavior is found when analyzing Small, and Medium Enterprises (SMEs) codes (FORSTER; LOUGHRAN; MCDONALD, 2009).

Regardless of the criticism around the focus on legal requirements in corporate codes, they remain the primary role in many corporations and, as Singh (2006) and Babri, Davidson \& Helin (2019) indicate, will remain an essential feature in compliance systems for many years to come. Having analyzed the elements of legal codes, we now turn to the study of behavioral contributions to corporate codes.

\subsubsection{Behavioral Perspective}

A pure cost-benefit analysis of legal codes leaves considerable aspects of human behavior behind (THALER; GANSER, 2015). For instance, how individuals perceive ethicality and what biases exist in human decision-making is often neglected when constructing compliance systems.

Although the definition of behavioral ethics is far from being consensual, one can point out to its main components. Bazerman \& Tenbrunsel (2011) define behavioral ethics as "a field that seeks to understand how people truly behave when confronted with ethical dilemmas" (p. 4). According to the authors, the ethical behavior of individuals is recurrently inconsistent, even contradictory at times. Due to human beings' erratic behavior, traditional approaches to ethics lack a thorough understanding of the unintentional yet predictable cognitive patterns that may result in unlawful behavior (BAZERMAN; TENBRUNSEL, 2011).

Of key importance to the behavioral ethics literature is the bounded ethicality concept. It can be described as a focus on "the psychological processes that lead even good people to engage in ethically questionable behavior that contradicts their preferred ethics" (BAZERMAN; TENBRUNSEL, 2011, p. 5). As claimed by the authors, the bounded ethicality concept comes into play when individuals' harmful decision is inconsistent with the decision maker's beliefs and preferences. That is when the ability to conceptualize a 
decision in ethical terms is impaired or bounded.

Besides bounded ethicality, the bounded awareness concept is recurrently studied by behavioral researchers. The term has many different names depending on the school of thought and can be found as inattentional blindness, focusing illusion, focalism, and framing effects (SCHKADE; KAHNEMAN, 1998; WILSON et al., 2000; KAHNEMAN, 2011). According to (BAZERMAN; TENBRUNSEL, 2011), bounded awareness refers to the habitual tendency of excluding essential and relevant information from one's decisionmaking processes by placing biased bounds and limitations around the definition of the problem. This unconscious disregard of information has significant consequences for the framing of decisions and, consequently, to the decision outcome's ethicality.

Changing from the individual level to the organizational, Treviño, Weaver \& Reynolds (2006) develop a comprehensive review of how behavioral ethics can enhance organizations' ethical outcomes. For example, bounded awareness is important for understanding the phenomena described by Soltes (2016), who mainly focuses on the reasons for white-collar crime and the rationale behind these unlawful conducts. As claimed by Bazerman \& Sezer (2016), it is often the case that the perpetrators were surrounded by individuals who were clearly in a position to recognize the misbehavior and did not take action. Bounded awareness allows the perpetuation of frauds through the mechanism of decreasing one's ability to identify and notice activities that may raise questions from an ethical perspective. When many individuals assume this behavior, the misconduct can perpetuate itself for a considerable period without arousing suspicion (BAZERMAN; SEZER, 2016).

Notwithstanding the fact that much of the behavioral ethicists' focus has been on unconscious actions and its unintended ethical consequences, the different approaches for conscious versus unconscious deliberations are present in both bounded ethicality and bounded awareness concepts: even though the unconscious component has a significant influence in ethical decision-making (ZHANG; GINO; BAZERMAN, 2014), when the consciousness of an individual can interpret an ethical situation, then it becomes a choice to disregard or not the information presented. Albeit the dismissal process itself is also immersed within biases of its own, it is still a conscious deliberative action (KAHNEMAN, 2011).

The resulting phenomenon of bounded awareness and ethicality falls within the created ethical gaps: the difference between one's perceived ethicality (i.e., the individual's image of the ethical standards practices) versus the actual incurred ethical decisions made by the individual. This gap - although easily inferred in others- is ordinarily opaque to the decision-maker itself (BAZERMAN; TENBRUNSEL, 2011). Although normally individually-focused, the concept is present in organizations as well. The gap effect in organizations is compounded by the individual gaps in the company's employees. Group 
work, groupthink, and fictional boundaries are additional factors that impede organizations from perceiving the circumstances though an ethical point of view (BAZERMAN; TENBRUNSEL, 2011).

2.3.3 A New Categorization of Codes: Legal and Behavior Perspectives

From the previous categorization variables, we propose four different clusters, depending on the share of the code which is dedicated to behavioral or legal constructs. Figure 1 illustrates the theoretical constructs that are constructed.

Figure 1 - Theoretical Clusters

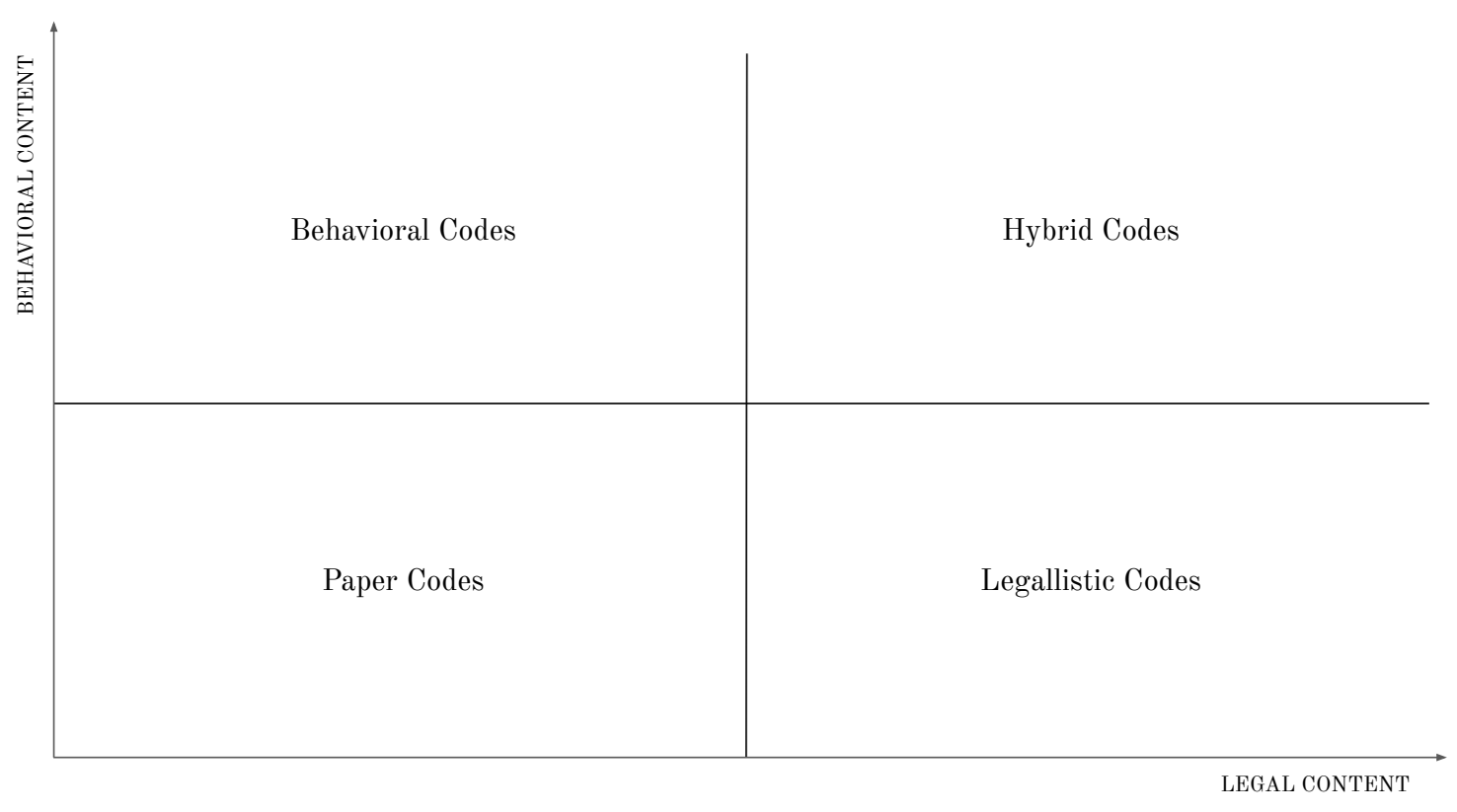

We classify them as the following:

- Paper Codes (-,-): Codes with low percentages of both legal and behavioral approaches. Following Soltes (2017) approach, we classify them as paper codes, that is, codes with the sole purpose of adhering to current rules in cases of external auditing and investigations, without effectively altering employee behavior.

- Legal Codes $(+,-)$ : Codes with high percentages of legal words, but low percentages of behavioral ones. They rely mainly on the rationality assumption and cost-benefit analysis of individual ethical decision-making, being heavily focused on the magnitude and probabilities of punishments, according to the applicable laws and shareholder demands.

- Behavioral Codes $(-,+)$ : Codes with high percentages of behavioral words, but low percentages of legal ones. These codes rely on less rational frameworks on 
human behavior, also considering emotional, social, and cultural variables on ethical decision-making.

- Hybrid Codes $(+,+)$ : Codes that have high percentages of both legal and behavioral content. These codes may embed many thinks from the standard rationality framework, which is characteristic of legal codes, but also take into consideration cultural and social factors that affect ethical decision-making.

\subsection{HYPOTHESES DEVELOPMENT}

As Soltes (2017) states:

"More than two decades after "effective compliance" entered discussions concerning corporate conduct, there continues to be significant ambiguity in understanding what "effective compliance" is on the part of both the legal system (i.e., courts, prosecutors, and regulators) and firms." (p. 1010)

Suppose we cannot empirically evaluate how these guidelines positively influence ethical decision-making internally and what message it transmits externally. In that case, we are once again in the realm of adding layers and complexity to organizations without any benefits - it becomes a pure transactional cost of setting up a corporate entity.

The compliance field presents itself as a mixture of an old endeavor with a newlyborn area's characteristics. Although billions are being spent on such measures, and hundreds of thousands of employees ${ }^{2}$ are currently employed in the field, the lack of consensus regarding what characteristics determine a robust system requires an answer.

The review pinpoints two main outcomes. First, that even with institutional changes pointing towards code adoption as a recommended path, it is still not a sine qua non condition for running an ethical business in today's environment. The code's effectiveness is always challenged, and no definite conclusion can be drawn, albeit its widespread use (as discussed in Doorey (2018)).

Second, we believe that the code's effectiveness dilemma is tightly linked to the lack of studies and categorization efforts that do not take into consideration the inner assumptions of ethical decision-making. We argue that if a code aims to foster better ethical behavior, it needs to consider and think about ethical decision-making assumptions and consequences of a code's content; otherwise, the guidelines are mere "paper codes" without any substantial impact on organizational outcomes. Omitting the discussion on how human behavior is modeled is a significant flaw and is closely linked to the scant

$\overline{2}$ As stated by Economist (2019) on their article on compliance at the banking sector, Citigroup, as an example, reported that it had 30.000 compliance staff at the end of 2018. JPMorgan, an astonishing 43.000 employees. 
robust evidence assessing the effectiveness of codes and compliance systems in general (HAUGH, 2017; SOLTES, 2017).

From the above discussion, we propose the following hypotheses:

H1. There exist different categories of corporate codes of ethics depending on their legal and/or behavioral orientation.

H2. Different code's orientation - legal and/or behavior - have different effects on corporate ethical behavior.

It is worth noting that our second hypothesis does not suggest that a pure behavioral code should produce a better outcome than a purely legal one, or vice-versa. We refrain from discussing such theoretical battle as there is a scant probability of it being empirically tested. 


\section{METHODS}

\subsection{SAMPLE}

To examine our hypotheses, we use a sample of Fortune 500 firms in 2017. First, by relying on American firms, we hold constant possible cultural factors, which could significantly impact ethical behavior and outcomes (OUMLIL; BALLOUN, 2017). Second, Fortune 500 firms are of economic importance, representing around two-thirds of the U.S. GDP in 2017 (MAGAZINE, 2017). Finally, because of their economic relevance, the Stock and Exchange Commission (SEC), since the corporate governance scandals outbreak in the U.S. in 2001, closely monitor material information regarding those companies, including not only financial and accounting information but also environmental and product liabilities (see Securities \& Commission (2003)).

For each of Fortune 500 firm, we analyze their latest code available at the Compliance Database from the University of Houston Law Center. This dataset includes codes from Fortune 500 companies ranging from 2012 to 2019. We choose the 2017 code for two main reasons: (1) to avoid using codes that are too distant in time and, therefore, likely to have been already updated; and (ii) to have a big enough sample size to perform our analysis. It is noteworthy to state that we excluded codes addressing specific targets such as supplier's codes of conduct and codes directed at the board of directors. We aim to evaluate codes targeting the entire organization, including employees and external stakeholders. Our final sample consists of 493 firms from the Fortune 500 with complete information.

Figure 2 highlights the sector breakdown of the companies analyzed in this article. It is important to emphasize that seven companies did not have an active code according to the Compliance Database, and therefore were excluded from the remaining analysis.

Figure 2 - 2017 Fortune 500 Breakdown per Sector

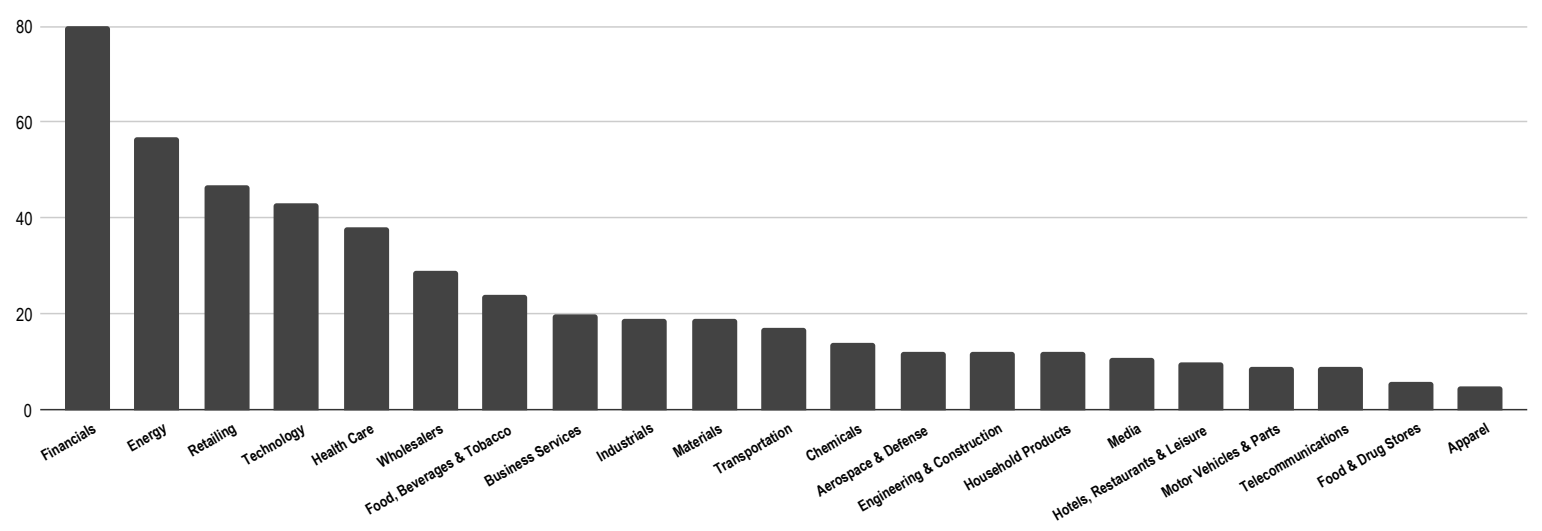


We find an adoption rate of $98.6 \%$. Our results are in accordance with previous estimates from Kowalczyk-Hoyer (2014), which reported an adoption of around $97 \%$ and are slightly higher than code adoption percentages found in previous studies analyzed in the Literature Review section. As the dataset considered only conglomerates headquartered in the US, it is no surprise that code adoption was almost unanimous. Given the institutional environment of the US, together with rule 204A-1 of the SEC, it would be expected that virtually every company would have its code.

We will not restrict our analysis to only a defined form of ownership (public or private). However, as expected, the majority of our sample are public companies (479 out of the 493 firms). Our sample size is a considerable improvement when compared to previous empirical studies, which generally examined smaller samples (e.g., Calderón, Ferrero \& Redin (2012) performed their analysis on a cohort of 50 companies).

Codes of ethics are often updated to adjust to institutional changes as well as to consider new corporate policies. Therefore, we fixed our period of analysis to evaluate the last available version of the codes in 2017, which is the Houston Law Center Database latest year. By setting codes' period, we also avoid endogeneity issues that may arise from policy changes derived prior company's misbehavior. Lastly, it is important to mention that all the codes were taken after significant institutional changes, such as the 2002 Sarbanes-Oxley Act or the 2010 Dodd-Frank Act. We are not aware of any breakthroughs in terms of institutional settings that occurred between 2017 and 2019.

The format and content of the codes come in different forms and shapes: codes ranging from one page up to 86 pages, and from fewer than 500 words up to 21,000. On average, codes from Fortune 500 companies have approximately 29 pages, with around 8,571 words each. However, one has to be careful in analyzing the aggregate average, as there might be industry-specific effects present. Indeed, we observe that codes' total number of words from the Apparel sector has a much lower standard deviation when compared to the financial sector. In any case, it is clear to see that there are considerable differences in code size in almost every sector, indicating that there is no 'one-size-fits-all' compliance policy per industry. Table 2 presents the summary statistics of our sample. 
Table 2 - Codes' Number of Pages and Words per Sector

\begin{tabular}{|c|c|c|c|c|c|c|}
\hline & \multicolumn{3}{|c|}{ Code: Number of Pages } & \multicolumn{3}{|c|}{ Code: Number of Words } \\
\hline & Minimum & Average & Maximum & Minimum & Average & Maximum \\
\hline Aerospace \& Defense & 4 & 27 & 72 & 6,853 & 9,822 & 12,337 \\
\hline Apparel & 6 & 28 & 82 & 2,854 & 6,431 & 9,244 \\
\hline Business Services & 3 & 21 & 47 & 1,509 & 8,049 & 15,414 \\
\hline Chemicals & 2 & 29 & 78 & 485 & 10,468 & 16,376 \\
\hline Energy & 1 & 32 & 58 & 1,732 & 8,178 & 14,605 \\
\hline Engineering \& Construction & 7 & 23 & 52 & 3,616 & 10,092 & 17,262 \\
\hline Financials & 8 & 34 & 86 & 1,463 & 8,741 & 21,192 \\
\hline Food \& Drug Stores & 2 & 30 & 60 & 2,917 & 8,954 & 17,358 \\
\hline Food, Beverages \& Tobacco & 6 & 28 & 48 & 2,789 & 9,459 & 17,666 \\
\hline Health Care & 7 & 27 & 58 & 507 & 9,001 & 18,555 \\
\hline Hotels, Restaurants \& Leisure & 6 & 36 & 66 & 7,132 & 11,104 & 17,328 \\
\hline Household Products & 4 & 35 & 64 & 968 & 8,297 & 13,781 \\
\hline Industrials & 21 & 36 & 52 & 1,918 & 8,108 & 15,371 \\
\hline Materials & 9 & 26 & 38 & 2,649 & 7,683 & 13,877 \\
\hline Media & 2 & 28 & 54 & 2,444 & 9,824 & 16,055 \\
\hline Motor Vehicles \& Parts & 6 & 33 & 58 & 2,285 & 8,389 & 16,104 \\
\hline Retailing & 21 & 32 & 52 & 1,079 & 7,235 & 19,865 \\
\hline Technology & 4 & 28 & 60 & 562 & 8,056 & 14,805 \\
\hline Telecommunications & 11 & 32 & 59 & 2,786 & 9,798 & 18,249 \\
\hline Transportation & 15 & 25 & 46 & 2,207 & 10,685 & 21,625 \\
\hline Wholesalers & 6 & 29 & 48 & 2,651 & 7,185 & 12,549 \\
\hline TOTAL & 1 & 29 & 86 & 485 & 8,571 & 21,625 \\
\hline
\end{tabular}

\subsection{VARIABLES}

\subsubsection{Code Effectiveness}

\subsubsection{Risk of Misconduct}

To assess the codes' effectiveness, we use the two proxies for corporate ethical behavior. Drawing upon RepRisk AG databases, we construct two measures for the risk of corporate misbehavior, more specifically: (i) the Environmental, Social and Corporate Governance (ESG) Issues, and (ii) the United Nations Global Compact (UNGC) Principles Violations. We gather information from companies' ESG issues and UNGC violations from 2017 to 2019.

The RepRisk' ESG Issues consists of high, medium, and low impact issues in each of the three dimensions (Environmental, Social, and Governance). These are count variables (i.e., count the number of issues and violations), and are zero-inflated, as many companies do not have issues or violations during the timeframe considered. Table 3 highlights each issue category, as well as the breakdown across severity levels. 
Table 3 - ESG Issues Breakdown per ESG Issue Type

\begin{tabular}{|c|c|c|c|}
\hline \multirow[b]{2}{*}{ Issue } & \multicolumn{3}{|c|}{ Issue Impact Category } \\
\hline & High & Medium & Low \\
\hline Animal mistreatment & 0 & 6 & 14 \\
\hline Anti-competitive practices & 0 & 43 & 150 \\
\hline Child labor & 2 & 13 & 33 \\
\hline Climate change, GHG emissions and global pollution & 0 & 14 & 94 \\
\hline Controversial products and services & 2 & 64 & 84 \\
\hline Corruption, bribery, extortion and money laudering & 1 & 47 & 78 \\
\hline Discrimination in employment & 1 & 26 & 74 \\
\hline Executive compensation issues & 0 & 5 & 18 \\
\hline Forced labor & 1 & 19 & 28 \\
\hline Fraud & 3 & 130 & 177 \\
\hline Freedom of association and collective bargaining & 0 & 10 & 18 \\
\hline Human rights abuses and corporate complicity & 7 & 77 & 255 \\
\hline Impacts on communities & 1 & 132 & 215 \\
\hline Impacts on landscapes, ecosystems and biodiversity & 1 & 84 & 182 \\
\hline Local participation issues & 1 & 7 & 20 \\
\hline Local pollution & 2 & 75 & 160 \\
\hline Misleading communication & 1 & 21 & 35 \\
\hline Occupational health and safety issues & 3 & 43 & 77 \\
\hline Other environmental issues & 0 & 0 & 0 \\
\hline Other issues & 0 & 0 & 1 \\
\hline Other social issues & 0 & 0 & 0 \\
\hline Overuse and wasting of resources & 0 & 0 & 4 \\
\hline Poor employment conditions & 3 & 74 & 124 \\
\hline Products (health and environmental issues) & 2 & 59 & 352 \\
\hline Social discrimination & 0 & 10 & 44 \\
\hline Supply chain issues & 4 & 90 & 329 \\
\hline Tax evasion & 1 & 12 & 29 \\
\hline Tax optimization & 0 & 23 & 63 \\
\hline Violation of international standards & 0 & 9 & 11 \\
\hline Violation of national legislation & 5 & 286 & 597 \\
\hline Waste issues & 2 & 23 & 76 \\
\hline TOTAL & 43 & 1402 & 3342 \\
\hline
\end{tabular}

Summing up to each ESG dimension, Table 4 shows that more than $50 \%$ of the ESG issues were governance-related, while the other $25 \%$ is almost evenly divided between environmental and social topics. It should be emphasized that we expect the code's content to impact all three of ESG dimensions, and therefore the whole dataset will be used to assess code effectiveness.

Table 4 - ESG Issues Breakdown per ESG category

\begin{tabular}{lrrrr}
\hline Issue & High & Medium & Low & TOTAL \\
\hline Environmental-related & 7 & 261 & 882 & $\mathbf{1 1 5 0}$ \\
Social-related & 19 & 411 & 888 & $\mathbf{1 3 1 8}$ \\
Governance-related & 17 & 730 & 1571 & $\mathbf{2 3 1 8}$ \\
Others & 0 & 0 & 1 & $\mathbf{1}$ \\
\hline
\end{tabular}

Regarding the UNGC violations ${ }^{1}$ database, it consists of violations on each principle, ranging from one to ten, and also breakdown between severity levels, depending on the influence or readership of the source in which the risk incident was published, as exemplified in Table 5.

1 For more information on the UNGC Principles, please check the UNGC website at $<$ www. unglobalcompact.org/what-is-gc/mission/principles $>$ 
Table 5 - Violations Breakdown per UNGC Principle

\begin{tabular}{lrrr}
\hline & \multicolumn{3}{c}{ UNGC Severity } \\
\cline { 2 - 4 } UNGC Principles & High & Medium & Low \\
\hline Principle 1 (Human Rights) & 11 & 219 & 721 \\
Principle 2 (Human Rights) & 10 & 145 & 596 \\
Principle 3 (Labor) & 1 & 23 & 38 \\
Principle 4 (Labor) & 4 & 34 & 38 \\
Principle 5 (Labor) & 4 & 22 & 42 \\
Principle 6 (Labor) & 3 & 36 & 141 \\
Principle 7 (Environment) & 4 & 205 & 490 \\
Principle 8 (Environment) & 4 & 205 & 490 \\
Principle 9 (Environment) & 4 & 205 & 490 \\
Principle 10 (Anti-corruption) & 2 & 92 & 175 \\
TOTAL & $\mathbf{4 7}$ & $\mathbf{1 1 8 6}$ & $\mathbf{3 2 2 1}$ \\
\hline
\end{tabular}

Again categorizing each principle, we find that human rights and environmental violations comprise most of the dataset. Table 6 summarizes the dataset.

Table 6 - Violations Breakdown per UNGC Category

\begin{tabular}{lrrrr}
\hline & \multicolumn{4}{c}{ UNGC Severity } \\
\cline { 2 - 5 } UNGC Categories & High & Medium & Low & TOTAL \\
\hline Human Rights & 21 & 364 & 1317 & 1702 \\
Labour & 12 & 115 & 259 & 386 \\
Environment & 12 & 615 & 1470 & 2097 \\
Anti-Corruption & 2 & 92 & 175 & 269 \\
\hline
\end{tabular}

Looking at the number of RepRisk ESG issues, we observe an apparent concentration in some sectors, especially when considering high severity cases. In general, there are sectors which, during the period considered, have very different exposures. For instance, we observe that none of the Apparel industry companies have faced any high, medium, or low severity ESG issues. In contrast, sectors such as Technology, Retailing, and Food \& Drug Stores had significant events. Table 7 summarizes the distribution per category and issue severity. 
Table 7 - ESG Issues Breakdown per Sector and per Severity

\begin{tabular}{|c|c|c|c|c|c|c|c|c|c|}
\hline & \multicolumn{3}{|c|}{ High Severity } & \multicolumn{3}{|c|}{ Medium Severity } & \multicolumn{3}{|c|}{ Low Severity } \\
\hline & Interval & Total & Avg. & Interval & Total & Avg. & Interval & Total & Avg. \\
\hline Aerospace \& Defense & {$[0,2]$} & 2 & 0.17 & {$[0,53]$} & 94 & 7.83 & {$[0,56]$} & 129 & 10.75 \\
\hline Apparel & {$[0,0]$} & 0 & 0.00 & {$[0,0]$} & 0 & 0.00 & {$[0,0]$} & 0 & 0.00 \\
\hline Business Services & {$[0,0]$} & 0 & 0.00 & {$[0,4]$} & 4 & 0.20 & {$[0,2]$} & 2 & 0.10 \\
\hline Chemicals & {$[0,0]$} & 0 & 0.00 & {$[0,83]$} & 128 & 9.14 & {$[0,116]$} & 211 & 15.07 \\
\hline Energy & {$[0,0]$} & 0 & 0.00 & {$[0,199]$} & 401 & 7.04 & {$[0,275]$} & 817 & 14.33 \\
\hline Engineering \& Construction & {$[0,0]$} & 0 & 0.00 & {$[0,25]$} & 25 & 2.08 & {$[0,48]$} & 61 & 5.08 \\
\hline Financials & {$[0,4]$} & 4 & 0.05 & {$[0,136]$} & 293 & 3.66 & {$[0,266]$} & 553 & 6.91 \\
\hline Food \& Drug Stores & {$[0,0]$} & 0 & 0.00 & {$[0,53]$} & 100 & 16.67 & {$[0,132]$} & 248 & 41.33 \\
\hline Food, Beverages \& Tobacco & {$[0,0]$} & 0 & 0.00 & {$[0,36]$} & 49 & 2.04 & {$[0,135]$} & 145 & 6.04 \\
\hline Health Care & {$[0,0]$} & 0 & 0.00 & {$[0,34]$} & 99 & 2.61 & {$[0,50]$} & 119 & 3.13 \\
\hline Hotels, Restaurants \& Leisure & {$[0,0]$} & 0 & 0.00 & {$[0,0]$} & 0 & 0.00 & {$[0,0]$} & 0 & 0.00 \\
\hline Household Products & {$[0,0]$} & 0 & 0.00 & {$[0,58]$} & 66 & 5.50 & {$[0,67]$} & 89 & 7.42 \\
\hline Industrials & {$[0,0]$} & 0 & 0.00 & {$[0,99]$} & 111 & 5.84 & {$[0,121]$} & 162 & 8.53 \\
\hline Materials & {$[0,0]$} & 0 & 0.00 & {$[0,10]$} & 14 & 0.74 & {$[0,62]$} & 87 & 4.58 \\
\hline Media & {$[0,0]$} & 0 & 0.00 & {$[0,42]$} & 47 & 4.27 & {$[0,105]$} & 164 & 14.91 \\
\hline Motor Vehicles \& Parts & {$[0,0]$} & 0 & 0.00 & {$[0,11]$} & 14 & 1.56 & {$[0,15]$} & 15 & 1.67 \\
\hline Retailing & {$[0,0]$} & 0 & 0.00 & {$[0,47]$} & 138 & 2.94 & {$[0,392]$} & 921 & 19.60 \\
\hline Technology & {$[0,30]$} & 37 & 0.86 & {$[0,343]$} & 502 & 11.67 & {$[0,929]$} & 1335 & 31.05 \\
\hline Telecommunications & {$[0,0]$} & 0 & 0.00 & {$[0,21]$} & 30 & 3.33 & {$[0,21]$} & 39 & 4.33 \\
\hline Transportation & {$[0,0]$} & 0 & 0.00 & {$[0,29]$} & 51 & 3.00 & {$[0,80]$} & 133 & 7.82 \\
\hline Wholesalers & {$[0,0]$} & 0 & 0.00 & {$[0,91]$} & 174 & 6.00 & {$[0,90]$} & 153 & 5.28 \\
\hline TOTAL & {$[0,30]$} & 43 & 0.09 & {$[0,343]$} & 2340 & 4.75 & {$[0,929]$} & 5383 & 10.92 \\
\hline
\end{tabular}

UNGC violations follow the same structure as the number of ESG issues. However, it is important to highlight some differences. Firstly, we notice that, while still highly concentrated, the number of violations is more evenly distributed (e.g., low severity violations across all sectors). Besides, some sectors which did not stand out in our ESG issues analysis, such as Chemicals, are significantly impacted by UNGC violations. Table 8 gives an overview of the violations structure.

Table 8 - UNGC Violations Breakdown per Sector and per Severity

\begin{tabular}{|c|c|c|c|c|c|c|c|c|c|}
\hline & \multicolumn{3}{|c|}{ High Severity } & \multicolumn{3}{|c|}{ Medium Severity } & \multicolumn{3}{|c|}{ Low Severity } \\
\hline & Interval & Total & Avg. & Interval & Total & Avg. & Interval & Total & Avg. \\
\hline Aerospace \& Defense & {$[0,2]$} & 2 & 0.17 & {$[0,42]$} & 97 & 8.08 & {$[0,44]$} & 152 & 12.67 \\
\hline Apparel & {$[0,0]$} & 0 & 0.00 & {$[0,13]$} & 13 & 2.60 & {$[0,6]$} & 6 & 1.20 \\
\hline Business Services & {$[0,0]$} & 0 & 0.00 & {$[0,9]$} & 11 & 0.55 & {$[0,22]$} & 23 & 1.15 \\
\hline Chemicals & {$[0,0]$} & 0 & 0.00 & {$[0,106]$} & 202 & 14.43 & {$[0,142]$} & 302 & 21.57 \\
\hline Energy & {$[0,1]$} & 1 & 0.02 & {$[0,174]$} & 437 & 7.67 & {$[0,320]$} & 984 & 17.26 \\
\hline Engineering \& Construction & {$[0,0]$} & 0 & 0.00 & {$[0,20]$} & 21 & 1.75 & {$[0,28]$} & 41 & 3.42 \\
\hline Financials & {$[0,0]$} & 0 & 0.00 & {$[0,81]$} & 201 & 2.51 & {$[0,205]$} & 542 & 6.78 \\
\hline Food \& Drug Stores & {$[0,0]$} & 0 & 0.00 & {$[0,13]$} & 18 & 3.00 & {$[0,48]$} & 83 & 13.83 \\
\hline Food, Beverages \& Tobacco & {$[0,17]$} & 17 & 0.71 & {$[0,47]$} & 106 & 4.42 & {$[0,49]$} & 168 & 7.00 \\
\hline Health Care & {$[0,0]$} & 0 & 0.00 & {$[0,55]$} & 123 & 3.24 & {$[0,116]$} & 248 & 6.53 \\
\hline Hotels, Restaurants \& Leisure & {$[0,0]$} & 0 & 0.00 & {$[0,33]$} & 37 & 3.70 & {$[0,107]$} & 131 & 13.10 \\
\hline Household Products & {$[0,0]$} & 0 & 0.00 & {$[0,27]$} & 32 & 2.67 & {$[0,31]$} & 40 & 3.33 \\
\hline Industrials & {$[0,0]$} & 0 & 0.00 & {$[0,65]$} & 134 & 7.05 & {$[0,178]$} & 289 & 15.21 \\
\hline Materials & {$[0,0]$} & 0 & 0.00 & {$[0,38]$} & 55 & 2.89 & {$[0,52]$} & 100 & 5.26 \\
\hline Media & {$[0,0]$} & 0 & 0.00 & {$[0,17]$} & 19 & 1.73 & {$[0,36]$} & 43 & 3.91 \\
\hline Motor Vehicles \& Parts & {$[0,0]$} & 0 & 0.00 & {$[0,31]$} & 58 & 6.44 & {$[0,73]$} & 145 & 16.11 \\
\hline Retailing & {$[0,0]$} & 0 & 0.00 & {$[0,32]$} & 94 & 2.00 & {$[0,163]$} & 447 & 9.51 \\
\hline Technology & {$[0,21]$} & 27 & 0.63 & {$[0,135]$} & 260 & 6.05 & {$[0,599]$} & 1251 & 29.09 \\
\hline Telecommunications & {$[0,0]$} & 0 & 0.00 & {$[0,11]$} & 17 & 1.89 & {$[0,127]$} & 143 & 15.89 \\
\hline Transportation & {$[0,0]$} & 0 & 0.00 & {$[0,17]$} & 37 & 2.18 & {$[0,81]$} & 120 & 7.06 \\
\hline Wholesalers & {$[0,0]$} & 0 & 0.00 & {$[0,6]$} & 12 & 0.41 & {$[0,13]$} & 32 & 1.10 \\
\hline TOTAL & {$[0,21]$} & 47 & 0.10 & {$[0,174]$} & 1984 & 4.02 & {$[0,599]$} & 5290 & 10.73 \\
\hline
\end{tabular}




\subsubsection{Risk of Litigation}

When looking at an outcome perspective, we look at the risk of litigation from corporate misconduct. Therefore, we use the Securities Class Action Clearinghouse database (SCAC), compiled by the University of Stanford. The database provides over 4,000 lawsuits filed from 1998 up to 2019. The database consists of detailed information relating to the prosecution, defense, and settlement of federal class action securities fraud litigation. Once again, only litigations from 2017-2019 will be considered to rule out any inconsistencies related to endogeneity issues. Also, as class actions are available at the database only for public companies, we will restrict our dataset slightly to consider only these ownership models (479 companies). Given that we still have a very representative sample, we do not believe the consideration of only public companies will impact our analysis in any way. Table 9 summarizes the variable distribution.

Table 9 - Class Action Fillings Distributed by Industry Sector

\begin{tabular}{lrrr}
\hline & \multicolumn{3}{c}{ Class Action Litigations } \\
\cline { 2 - 4 } & Interval & Total & Avg. \\
\hline Aerospace \& Defense & {$[0,2]$} & 6 & 0.50 \\
Apparel & {$[0,0]$} & 0 & 0.00 \\
Business Services & {$[0,1]$} & 2 & 0.10 \\
Chemicals & {$[0,1]$} & 1 & 0.07 \\
Energy & {$[0,2]$} & 9 & 0.16 \\
Engineering \& Construction & {$[0,1]$} & 2 & 0.17 \\
Financials & {$[0,3]$} & 13 & 0.16 \\
Food \& Drug Stores & {$[0,1]$} & 3 & 0.50 \\
Food, Beverages \& Tobacco & {$[0,2]$} & 7 & 0.29 \\
Health Care & {$[0,2]$} & 16 & 0.42 \\
Hotels, Restaurants \& Leisure & {$[0,1]$} & 1 & 0.10 \\
Household Products & {$[0,2]$} & 4 & 0.33 \\
Industrials & {$[0,3]$} & 6 & 0.32 \\
Materials & {$[0,1]$} & 1 & 0.05 \\
Media & {$[0,1]$} & 3 & 0.27 \\
Motor Vehicles \& Parts & {$[0,3]$} & 6 & 0.67 \\
Retailing & {$[0,1]$} & 6 & 0.13 \\
Technology & {$[0,2]$} & 13 & 0.30 \\
Telecommunications & {$[0,2]$} & 5 & 0.56 \\
Transportation & {$[0,1]$} & 1 & 0.06 \\
Wholesalers & {$[0,1]$} & 6 & 0.21 \\
& & & \\
TOTAL & {$[\mathbf{0 , 3}]$} & $\mathbf{1 1 1}$ & $\mathbf{0 . 2 3}$ \\
\hline
\end{tabular}

The class action distribution resembles ESG Issues and UNGC violations, with some sectors having no observations (e.g., apparel) and others with a concentrated number of events (e.g., financials and technology).

\subsubsection{Code's Behavioral and Legal Content}

To examine the nature of code's, as discussed in Hypothesis 1, we need measures of both the legal and behavior structure of codes, and we use a content analysis technique (NEUENDORF, 2016). This methodology is widely adopted and is often used to study codes, as highlighted in Forster, Loughran \& McDonald (2009). To mitigate any risks related 
to subjectivity in content categorizations - a recurrent criticism of this methodology - we propose to use an external dictionary from accredited sources to create our main categorizations and mitigate any risk related to subjectivity or endogeneity.

For the legal dictionary, we use the LexPredict law dictionary, which is composed of the most common words used in litigations filed at US courts, which perfectly suits this project's objective. This dictionary has around 13,200 words and expressions and was updated in 2019, therefore comprising the most recent legal terms present in our codes dataset. Concerning the behavioral dictionary, we use the American Psychological Association (APA) glossary, which has the most relevant psychological research terms. The dictionary consists of around 25,800 words extracted directly from APA's website.

Table 10 exemplifies some of the terms present in each of the dictionaries used. It is noteworthy to add that the dictionaries were used as extracted from the data sources, which means that the same word might be present in both dictionaries. Given that less than $5 \%$ of the legal terms are present in the behavioral dictionary, and less than $0.1 \%$ of the behavioral dictionary is in the legal one, we opted to run the analysis without removing the duplicates.

Table 10 - Sample of Words into Legal and Behavioral Dictionaries

\begin{tabular}{|c|c|}
\hline Legal-Based Words & Behavioral-Based Words \\
\hline $\begin{array}{l}\text { Account, Act, Action, Addition, Advances, Affiliate, Agent, Agreement, Agreement, Any } \\
\text { Person, Applicable Law, Approval, Article, Asset, Assets, Assignment, Authority, Autho- } \\
\text { rized, Bank, Banks, Base, Basis, Benefit, Benefits, Board, Borrower, Business, Business } \\
\text { Day, Capital, Case, Cash, Certificate, Claim, Code, Collateral, Company, Compensation, } \\
\text { Condition, Consent, Construction, Contract, Contractor, Control, Corporation, Cost, } \\
\text { Costs, Court, Credit, Credit, Damage, Day, Days, Debt, Default, Delivery, Demand, } \\
\text { Directly, Director, Document, Documents, Duty, Effective Date, Employee, Employ- } \\
\text { ment, Entity, Equipment, Event, Existing, Expense, Expenses, Facility, Fee, Fees, Force, } \\
\text { Fund, Funds, Good, Guarantor, Immediately, In, Income, Indebtedness, Information, } \\
\text { Instrument, Insurance, Interest, Issued, Jurisdiction, Law, Lease, Lender, Liabilities, } \\
\text { Liability, Lien, Loan, Loan, Material, Materials, Month, Necessary, New, Note, Notes, } \\
\text { Notice, Obligation, Obligations, Office, Officer, Operation, Order, Outstanding, Owner, } \\
\text { Page, Part, Parties, Party, Pay, Payment, Period, Permit, Person, Plan, Portion, Price, } \\
\text { Principal, Proceeds, Project, Property, Provide, Purchase, Rate, Receipt, Received, } \\
\text { Regulation, Related, Remedy, Report, Request, Right, Rto, Sale, Section, Securities, } \\
\text { Security, Service, Services, State, Statement, States, Stock, Subsidiary, Substantially, } \\
\text { Successor, System, Taxes, Term, Termination, Title, Transaction, Use, Used, Warrants, } \\
\text { Warranty, Work, Writing. }\end{array}$ & $\begin{array}{l}\text { Affect, Affect Display, Affect Intensity, Affective Aggression, Analytic Psychology, Anchor- } \\
\text { ing Bias, Applied Psychology, Behavior, Behavior Analysis, Behavior Disorder, Behavior } \\
\text { Pattern, Bias, Citizen, Code Of Ethics, Collaboration, Collective, Collective Behavior, } \\
\text { Collective Conscience, Collective Consciousness, Community Inclusion, Confirmation Bias, } \\
\text { Conscience, Conscientiousness, Core Emotion, Creativity, Cultural Bias, Cultural Diver- } \\
\text { sity, Culture, Culture Change, Culture Clash, Decentralized Organization, Discrimination, } \\
\text { Diversity, Diversity Training, Emotion, Emotional Content, Environment, Environmental } \\
\text { Approach, Environmental Cognition, Ethical Code, Ethical Conflict, Ethical Consumerism, } \\
\text { Ethical Determinism, Ethical Dilemma, Ethical Imperative, Ethical Judgment, Ethics, } \\
\text { Experimental Ethics, Familiar, Familiarity, Family, Family Dynamics, Friendship, Group, } \\
\text { Group Acceptance, Group Behavior, Group Cohesion, Group Socialization, Human Nature, } \\
\text { Inclusion, Ingroup Bias, Leadership, Leadership Style, Nature, Normative Ethics, Organism, } \\
\text { Organizational Approach, Organizational Assessment, Person Perception, Persona, Person- } \\
\text { ality, Pride, Professional Ethics, Purpose, Purposeful Behavior, Relationship, Relationship } \\
\text { Leader, Respect, Safety Behavior, Safety Need, Safety Psychology, Self-Respect, Social, } \\
\text { Social Acceptance, Social Action, Social Behavior, Social Creativity, Social Discrimination, } \\
\text { Social Emotion, Social Group, Social Organism, Social Relationship, Subjectivism, Subjec- } \\
\text { tivity, Transformational Leadership, Trust, Unity, Visual Environment, Work Ethic, Work } \\
\text { Psychology. }\end{array}$ \\
\hline
\end{tabular}

Turning to the evaluation of the code's content, we observe that, on average, $21 \%$ of a code is considered to be related to legal topics. In contrast, around $10 \%$ is dedicated to behavioral words. At first glance, it might seem odd that, on average, a code has double more words related to legal than behavioral topics, given that our dictionary for behavioral content outreaches the legal dictionary in more than 10,000 words. However, this difference is indeed expected: as we have discussed during our Literature Review, the emergence of codes and compliance policies was due to legal concerns after new regulations surfaced. Therefore, given that the idea of embedding behavioral concepts is much newer, codes are still slowly embracing these concepts and are, currently, predominantly towards legal matters. Table 11 and 12 highlights the content breakdown per sector. 
Table 11 - Legal Perspective: Average Number of Words and Percentages

\begin{tabular}{|c|c|c|c|c|c|c|c|c|}
\hline & \multicolumn{4}{|c|}{ Average Number of Words } & \multicolumn{4}{|c|}{ Percentage } \\
\hline & Minimum & Average & Std. Dev & Maximum & Minimum & Average & Std. Dev & Maximum \\
\hline Aerospace \& Defense & 349 & 1,847 & 964 & 3,947 & $17.20 \%$ & $21.58 \%$ & $1.72 \%$ & $26.55 \%$ \\
\hline Apparel & 352 & 1,711 & 714 & 3,007 & $18.21 \%$ & $21.17 \%$ & $1.44 \%$ & $25.04 \%$ \\
\hline Business Services & 219 & 1,549 & 832 & 4,382 & $16.91 \%$ & $21.73 \%$ & $2.03 \%$ & $26.97 \%$ \\
\hline Chemicals & 81 & 1,651 & 792 & 3,156 & $14.41 \%$ & $20.48 \%$ & $2.00 \%$ & $25.13 \%$ \\
\hline Energy & 133 & 1,836 & 1,016 & 4,040 & $15.86 \%$ & $20.46 \%$ & $2.17 \%$ & $26.23 \%$ \\
\hline Engineering \& Construction & 655 & 1,550 & 620 & 2,814 & $16.81 \%$ & $21.71 \%$ & $1.84 \%$ & $25.91 \%$ \\
\hline Financials & 625 & 1,914 & 800 & 3,584 & $9.57 \%$ & $20.43 \%$ & $2.70 \%$ & $23.45 \%$ \\
\hline Food \& Drug Stores & 364 & 1,713 & 766 & 3,039 & $17.52 \%$ & $21.55 \%$ & $1.79 \%$ & $24.73 \%$ \\
\hline Food, Beverages \& Tobacco & 371 & 1,648 & 629 & 2,720 & $16.95 \%$ & $20.53 \%$ & $1.77 \%$ & $24.67 \%$ \\
\hline Health Care & 644 & 1,597 & 635 & 2,743 & $17.66 \%$ & $21.40 \%$ & $2.22 \%$ & $27.07 \%$ \\
\hline Hotels, Restaurants \& Leisure & 506 & 2,250 & 1,090 & 4,890 & $18.35 \%$ & $21.13 \%$ & $1.61 \%$ & $25.35 \%$ \\
\hline Household Products & 74 & 2,158 & 809 & 3,314 & $15.26 \%$ & $20.40 \%$ & $2.89 \%$ & $28.77 \%$ \\
\hline Industrials & 1,457 & 1,965 & 243 & 2,277 & $17.97 \%$ & $20.10 \%$ & $1.27 \%$ & $22.11 \%$ \\
\hline Materials & 902 & 2,117 & 705 & 3,330 & $18.77 \%$ & $21.30 \%$ & $1.94 \%$ & $24.94 \%$ \\
\hline Media & 224 & 1,707 & 938 & 3,055 & $16.46 \%$ & $20.94 \%$ & $2.08 \%$ & $23.60 \%$ \\
\hline Motor Vehicles \& Parts & 570 & 2,092 & 789 & 3,523 & $18.72 \%$ & $21.50 \%$ & $1.43 \%$ & $23.67 \%$ \\
\hline Retailing & 1,335 & 2,493 & 829 & 3,810 & $18.72 \%$ & $22.27 \%$ & $2.34 \%$ & $26.92 \%$ \\
\hline Technology & 469 & 1,762 & 1,126 & 3,489 & $18.98 \%$ & $21.07 \%$ & $1.70 \%$ & $25.05 \%$ \\
\hline Telecommunications & 474 & 2,147 & 1,245 & 3,975 & $17.01 \%$ & $21.81 \%$ & $4.09 \%$ & $31.69 \%$ \\
\hline Transportation & 579 & 1,940 & 1,227 & 3,893 & $19.85 \%$ & $21.71 \%$ & $1.63 \%$ & $24.14 \%$ \\
\hline Wholesalers & 688 & 1,364 & 481 & 1,802 & $18.79 \%$ & $21.68 \%$ & $2.92 \%$ & $25.41 \%$ \\
\hline TOTAL & 74 & 1,795 & 854 & 4,890 & $\mathbf{9 . 5 7 \%}$ & $21.17 \%$ & $2.03 \%$ & $31.69 \%$ \\
\hline
\end{tabular}

Table 12 - Behavioral Perspective: Average Number of Words and Percentages

\begin{tabular}{|c|c|c|c|c|c|c|c|c|}
\hline & \multicolumn{4}{|c|}{ Average Number of Words } & \multicolumn{4}{|c|}{ Percentage } \\
\hline & Minimum & Average & Std. Dev & Maximum & Minimum & Average & Std. Dev & Maximum \\
\hline Aerospace \& Defense & 131 & 841 & 432 & 1,776 & $6.89 \%$ & $9.82 \%$ & $1.06 \%$ & $12.48 \%$ \\
\hline Apparel & 185 & 826 & 385 & 1,692 & $8.07 \%$ & $10.04 \%$ & $1.22 \%$ & $13.79 \%$ \\
\hline Business Services & 96 & 703 & 397 & 2,057 & $7.23 \%$ & $9.72 \%$ & $1.20 \%$ & $13.19 \%$ \\
\hline Chemicals & 50 & 765 & 367 & 1,575 & $6.04 \%$ & $9.54 \%$ & $1.32 \%$ & $15.19 \%$ \\
\hline Energy & 50 & 995 & 533 & 1,808 & $8.88 \%$ & $11.15 \%$ & $1.58 \%$ & $14.72 \%$ \\
\hline Engineering \& Construction & 261 & 679 & 303 & 1,428 & $7.07 \%$ & $9.34 \%$ & $1.06 \%$ & $12.39 \%$ \\
\hline Financials & 217 & 856 & 374 & 1,811 & $4.54 \%$ & $9.03 \%$ & $1.24 \%$ & $10.77 \%$ \\
\hline Food \& Drug Stores & 135 & 782 & 370 & 1,547 & $8.17 \%$ & $9.69 \%$ & $1.16 \%$ & $13.65 \%$ \\
\hline Food, Beverages \& Tobacco & 178 & 812 & 293 & 1,343 & $8.36 \%$ & $10.62 \%$ & $4.29 \%$ & $27.42 \%$ \\
\hline Health Care & 270 & 768 & 367 & 1,432 & $8.73 \%$ & $9.95 \%$ & $1.47 \%$ & $14.96 \%$ \\
\hline Hotels, Restaurants \& Leisure & 217 & 1,085 & 521 & 2,275 & $8.78 \%$ & $10.19 \%$ & $1.45 \%$ & $13.18 \%$ \\
\hline Household Products & 58 & 986 & 369 & 1,486 & $8.37 \%$ & $9.66 \%$ & $1.40 \%$ & $12.99 \%$ \\
\hline Industrials & 709 & 969 & 140 & 1,191 & $8.55 \%$ & $9.90 \%$ & $0.77 \%$ & $11.01 \%$ \\
\hline Materials & 288 & 949 & 383 & 1,689 & $7.96 \%$ & $9.28 \%$ & $0.67 \%$ & $10.37 \%$ \\
\hline Media & 80 & 778 & 428 & 1,352 & $7.54 \%$ & $9.40 \%$ & $1.77 \%$ & $14.26 \%$ \\
\hline Motor Vehicles \& Parts & 225 & 877 & 341 & 1,472 & $7.13 \%$ & $9.04 \%$ & $1.40 \%$ & $12.78 \%$ \\
\hline Retailing & 651 & 1,045 & 299 & 1,480 & $8.20 \%$ & $9.41 \%$ & $0.75 \%$ & $10.76 \%$ \\
\hline Technology & 203 & 762 & 481 & 1,394 & $8.26 \%$ & $9.08 \%$ & $0.75 \%$ & $10.36 \%$ \\
\hline Telecommunications & 310 & 965 & 487 & 1,761 & $7.76 \%$ & $10.83 \%$ & $3.91 \%$ & $19.85 \%$ \\
\hline Transportation & 343 & 861 & 489 & 1,686 & $7.87 \%$ & $10.16 \%$ & $1.49 \%$ & $11.76 \%$ \\
\hline Wholesalers & 307 & 595 & 199 & 805 & $8.23 \%$ & $9.51 \%$ & $0.98 \%$ & $10.76 \%$ \\
\hline TOTAL & 50 & 836 & 407 & 2,275 & $4.54 \%$ & $9.85 \%$ & $1.61 \%$ & $27.42 \%$ \\
\hline
\end{tabular}

Based upon these dictionaries, we counted the number of legal and behavior words for each Fortune 500's code to create our legal and behavior variables as follows:

$$
\begin{aligned}
& \ln B C_{i}=\ln \left(\frac{B C_{i}}{T W_{i}-B C_{i}-L C_{i}}\right) \\
& \ln L C_{i}=\ln \left(\frac{L C_{i}}{T W_{i}-B C_{i}-L C_{i}}\right)
\end{aligned}
$$

Where $B C_{i}$ is the total amount of categorized behavioral terms inside the code from company $i$. $L C_{i}$ follows the same rationale with regards to the legal terms. Finally, 
$T W_{i}$ is code $i$ total number of words.

Given that our behavioral and legal variables are, by definition, compositional data (i.e., $\frac{B C_{i}}{T W_{i}}+\frac{L C_{i}}{T W_{i}}+\frac{U C_{i}}{T W_{i}} \approx 1$ ), the above construction has important properties of mitigation possible independence violations which arise from using proportions as a unit of analysis. (AITCHISON, 1982; FRY; FRY; MCLAREN, 2000; BASINGER; CANN; ENSLEY, 2012).

Also, to account for industry heterogeneity that can have a pervasive impact on the number of events a company is exposed, we define industry-adjusted measures as follows:

$$
\begin{aligned}
& R_{\ln B C_{i}}=\ln B C_{i}-\bar{\mu}_{\ln B C s} \\
& R_{\ln L C_{i}}=\ln L C_{i}-\bar{\mu}_{\ln L C s} \\
& Z_{\ln B C_{i}}=\frac{\ln B C_{i}-\bar{\mu}_{\ln B C s}}{\sigma_{\ln B C}} \\
& Z_{\ln L C_{i}}=\frac{\ln L C_{i}-\bar{\mu}_{\ln L C s}}{\sigma_{\ln L C}}
\end{aligned}
$$

Where $\bar{\mu}_{\ln B C s}$ and $\bar{\mu}_{\ln L C s}$ is the average value of $\ln B C$ and $\ln L C$ in sector $s$, respectively. We, therefore, have two different industry adjusted measures: one captures the relative position to the industry mean (i.e., $R_{\ln B C_{i}}$ and $R_{\ln L C_{i}}$, and another that calculates the $\mathrm{z}$ score of these relative measures (i.e., $Z_{\ln B C_{i}}$ and $Z_{\ln L C_{i}}$. Both measures are used in our analysis to evaluate the robustness of our findings.

\subsubsection{Control Variables}

We are conscious that the Fortune 500 companies, despite their importance and group-like treatment, are still a heterogeneous group. Therefore, we consider a wide variety of control variables such as size (measured by the natural logarithm of firm's total assets), accounting performance (measured by the return on assets, ROA), and the location of the firm's headquarters (measured by the incorporation states). We gather the accounting measures from Compustat, using 2017 as the reference year.

\subsection{ESTIMATION METHODS}

\subsubsection{Cluster Analysis}

Hypothesis 1 suggests that there are different categories for the firm's codes, depending on their legal or behavior orientation. We, therefore, perform a cluster analysis that has been proposed as an appropriate method to examine interrelated dimensions for the discovery of insightful conceptualizations (GRIMMER; KING, 2011). 
Given this article is centered in terms of legal and behavioral categorizations, we use the legal, $\ln L C_{i}$, and behavior, $\ln B C_{i}$, variables as described in equations (3.1) and (3.2) above. We employ a hierarchical cluster analysis using Ward's minimum variance linkage algorithm. Given that outliers may influence the results, we prefer to use algorithms more robust to such unusual observations, instead of more sensitive complete or single-linkage methods.

Our measure of distance is the Mahalanobis distance. This is because our variables are correlated, and the Mahalanobis distance accounts for this phenomenon. Also, as both variables have the same distance scale, no standardization procedure is required (HAIR, 2011). Nonetheless, other measures of distance are used to evaluate our model robustness to different a priori settings.

As a post-processing method for clearly identifying how many groups were identified by the hierarchical clustering, we use both Duda-Hart and Calinski-Harabasz methods to assess the optimal amount of clusters are present in our data and that, eventually, resonates with our theoretical assumptions (EVERITT et al., 2011).

\subsubsection{Regression Analysis}

With the evaluation of the first hypothesis on hand - that is, whether we indeed find different categories based on the legal and behavioral content of codes - we desire to test how they influence the code effectiveness of each organization. To perform this analysis, however, it is crucial to examine and define the best regression analysis model given the variables we are considering. Considering that our dependent variable is specified on the positive domain and are count data, we will resort to transformed OLS models or zero-inflated models, depending on the dependent variable at stake (WOOLDRIDGE, 2015).

\subsubsection{Risk of Misbehavior}

To deal with this environment, we propose to use regression models that explicitly take into account the characteristics inherent to the dataset used. Moreover, given that there are many companies without any ESG issues or UNGC violations each year, it is expected that our dependent variable distribution is zero-inflated. Therefore, to cope with the data particularities, we choose methods such as Zero-Inflated Poisson and Negative Binomial regressions, which are well suited for this type of environment.

Therefore, with all relevant variables highlighted, we propose the following model:

$$
E_{i}=\alpha+\left(\beta_{1}\right) \ln B C_{i}+\left(\beta_{2}\right) \ln L C_{i}+\left(\beta_{3}\right) R O A+\left(\beta_{4}\right) S i z e+\varepsilon_{i}
$$

Where $E_{i}$ is the number of events (ESG issues or UNGC violations) of company $i$ 
during the timeframe considered (2017 to 2019), given that we are using a zero-inflated model, all independent variables have beta coefficients related to the inflated model. In order to adapt to our relative and z-score measures constructed in equations 3.3, 3.4, 3.5 and 3.6, the equation remains the same, substituting $\ln B C_{i}$ and $\ln L C_{i}$ with the corresponding metrics.

As explained in section 3.2.3, the control variables are essential to reduce the influence and correlation of a company's size with the number of events. Considering that we intend to isolate the effect of a code's structure on litigation, such controls are essential to separate the desired result. Besides size and ROA, we will also evaluate controlling the incorporation state with a dummy variable when Delaware is the state of incorporation. We have plenty of evidence showing that Delaware has an institutional framework that can also influence the number of events a company faces (GRINSTEIN; ROSSI, 2016; IV, 2017). Our models will test both with and without this dummy variable included in the robust standard error measure to evaluate the replicability of our results.

\subsubsection{Risk of Litigation}

With regards to the risk of possible class actions stakeholders might file against the company, we understand that code content can influence the misconduct behavior (as discussed in the previous topic), as well as directly impacting the risk of litigations, given that corporate codes are recurrent documents used in court procedures, as Loblaws' case highlighted. Figure 3 highlights our understanding of the relationship between the three constructs.

Figure 3 - Relationship Between Code Content, Misbehavior and Litigation Outcomes

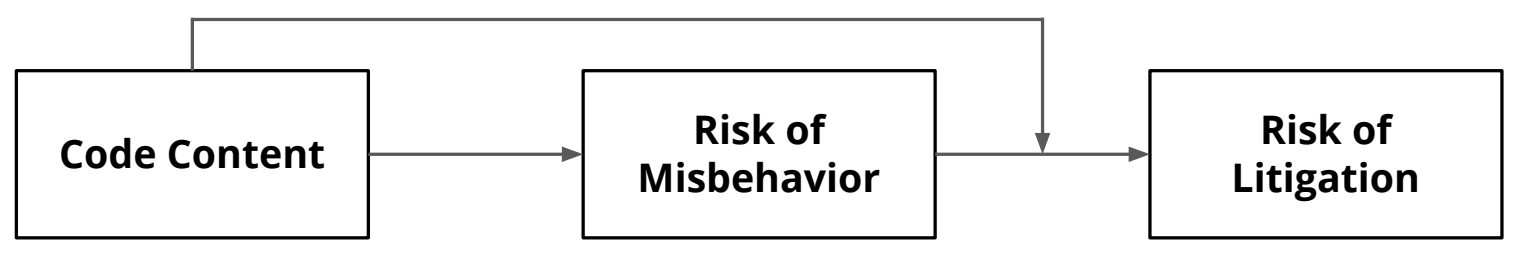

Figure 3 shows a direct relationship between code orientation and the risk of litigation, as well as the possible interactions between the content variables and the interaction effect of code's content orientation in the relationship between risk of misbehavior and risk of litigation. Equation 3.8 presents the estimated model of Figure $3^{2}$

2 The algebraic derivation of Equation 3.8 is available from the authors upon request. 
Because of the quadratic relationships across constructs derived from Figure 3, we transformed the dependent variables from a count variable to a continuous one to estimate an OLS model instead of relying on more complex non-linear estimation that will affect the intepretation of our results. Given the number of observations and the less extreme distribution when compared to the RepRisk database, such transformation does not fundamentally alter the results.

$$
\begin{aligned}
\ln \text { ClassActions }= & \left.\left.\alpha+\left(\beta_{1}\right) \ln B C_{i}+\right) \beta_{2}\right) \ln L C_{i}+\left(\beta_{3}\right) \ln B C_{i} \ln L C_{i}+\left(\beta_{4}\right) \ln B C_{i}^{2} \\
& +\left(\beta_{5}\right) \ln L C_{i}^{2}+\left(\beta_{6}\right) R O A+\left(\beta_{7}\right) \text { Size }+\left(\beta_{8}\right) \text { Ind.Sector } \\
& +\left(\beta_{9}\right) \text { Delaware }+\varepsilon_{i}
\end{aligned}
$$

Where $\ln L C_{i}, \ln B C_{i}, R O A$ and Size are the same as in Equation 3.7. IndSector is our dummy variable to take into consideration fixed-industry effects, and Delaware is our incorporation state dummy.

We test our outcome regression model (Equation 3.8) in two ways: (i) with and (ii) without considering incorporation state as a dummy variable (i.e., whether or not the company is subject to Delaware's rules). In both models, to grasp the industry effects present in our risk analysis regression, we have considered them both as a control variable at the model and as clusters in the error term, allowing for intragroup correlation.

To better visualize the data, we present the result with the content variable re-scaled from 0 to 10. To achieve this variable re-scaling, the following steps were taken for each of the transformed variables:

$$
\begin{aligned}
\ln L C_{\text {rescaled } i} & =\frac{\ln L C_{i} * \min (\ln L C)}{\max (\ln L C)-\min (\ln L C)} * 10 \\
\ln B C_{\text {rescaled } i} & =\frac{\ln B C_{i} * \min (\ln B C)}{m a x(\ln B C)-\min (\ln B C)} * 10 \\
R_{\ln L C_{\text {rescaled } i}} & =\frac{R_{\ln L C_{i}} * \min \left(R_{\ln L C}\right)}{m a x\left(R_{\ln L C}\right)-\min \left(R_{\ln L C}\right)} * 10 \\
R_{\ln B C_{\text {rescaled } i}} & =\frac{R_{\ln B C_{i}} * \min \left(R_{\ln B C}\right)}{m a x\left(R_{\ln B C}\right)-m i n\left(R_{\ln B C}\right)} * 10 \\
Z_{\ln L C_{\text {rescaled } i}} & =\frac{Z_{\ln L C_{i}} * \min \left(Z_{\ln L C}\right)}{m a x\left(Z_{\ln L C}\right)-\min \left(Z_{\ln L C}\right)} * 10 \\
Z_{\ln B C_{\text {rescaled } i}} & =\frac{Z_{\ln B C_{i}} * \min \left(Z_{\ln B C}\right)}{m a x\left(Z_{\ln B C}\right)-m i n\left(Z_{\ln B C}\right)} * 10
\end{aligned}
$$

The re-scaling of variables does not affect the regression results and is a useful technique for visualization purposes, especially when we develop our predictive margins plots. 



\section{RESULTS}

\subsection{CLUSTER ANALYSIS}

As mentioned in section 3.3, we use the ln metrics of legal and behavioral content, Mahalanobis distance, and Ward's Linkage clustering method as our primary result. Additionally, to evaluate the robustness of our analysis, we also highlight other analyses that may change one or more parameters (for instance, changing the distance method and transforming the content variables). Also previously mentioned, we use Ward's method for the hierarchical cluster analysis with both Duda-Hart (DH) and Calinski-Harabasz $(\mathrm{CH})$ post-processing methods for evaluating the number of groups to be chosen. The analysis is summarize in Table 13.

Table 13 - Duda-Hart and Calinski Harabasz Stopping Rules

\begin{tabular}{|c|c|c|c|c|}
\hline \multirow{2}{*}{\multicolumn{2}{|c|}{$\begin{array}{c}\text { Calinski - Harabasz* } \\
\text { Number of Clusters }\end{array}$}} & \multicolumn{3}{|c|}{ Duda-Hart** } \\
\hline & & \multirow{2}{*}{$\begin{array}{r}\text { Number of Clusters } \\
1\end{array}$} & \multirow{2}{*}{$\begin{array}{r}\mathrm{Je}(2) / \mathrm{Je}(1) \\
0.86\end{array}$} & \multirow{2}{*}{$\begin{array}{r}\text { Pseudo T-Squared } \\
82.4\end{array}$} \\
\hline 2 & 82.4 & & & \\
\hline 3 & 173.9 & 2 & 0.53 & 173.3 \\
\hline 4 & 151.2 & 3 & 0.76 & 91.3 \\
\hline 5 & 150.2 & 4 & 0.61 & 142.7 \\
\hline 6 & 142.7 & 5 & 0.76 & 46.3 \\
\hline 7 & 145.8 & 6 & 0.60 & 53.4 \\
\hline 8 & 131.9 & 7 & 0.85 & 15.7 \\
\hline 9 & 118.2 & 8 & 0.75 & 43.6 \\
\hline 10 & 111.9 & 9 & 0.52 & 61.3 \\
\hline 11 & 108.8 & 10 & 0.87 & 7.0 \\
\hline 12 & 116.2 & 11 & 0.43 & 72.3 \\
\hline 13 & 129.0 & 12 & 0.59 & 24.2 \\
\hline 14 & 124.2 & 13 & 0.27 & 162.3 \\
\hline \multirow[t]{2}{*}{15} & 153.3 & 14 & 0.30 & 52.5 \\
\hline & & 15 & 0.03 & 249.8 \\
\hline
\end{tabular}

\footnotetext{
* The larger the values of $\mathrm{Je}(1) / \mathrm{Je}(2)$, the better. The smaller the values of Pseudo T-Squared, the better.

** The larger the values of Pseudo-F, the better.
}

It is clear to see that, combining both the theoretical background and the cluster analysis, three main clusters can be identified using the hierarchical clustering methods. While CH clearly shows three clusters as the global optimum, DH method do have clustering optimums above the theoretical threshold of four. Given that these pulverized clusters have no underpinnings on our theory, we will continue our evaluation with the three defined groups. These clusters are exemplified in Figure 4. 
Figure 4 - Theoretical Clusters Concept

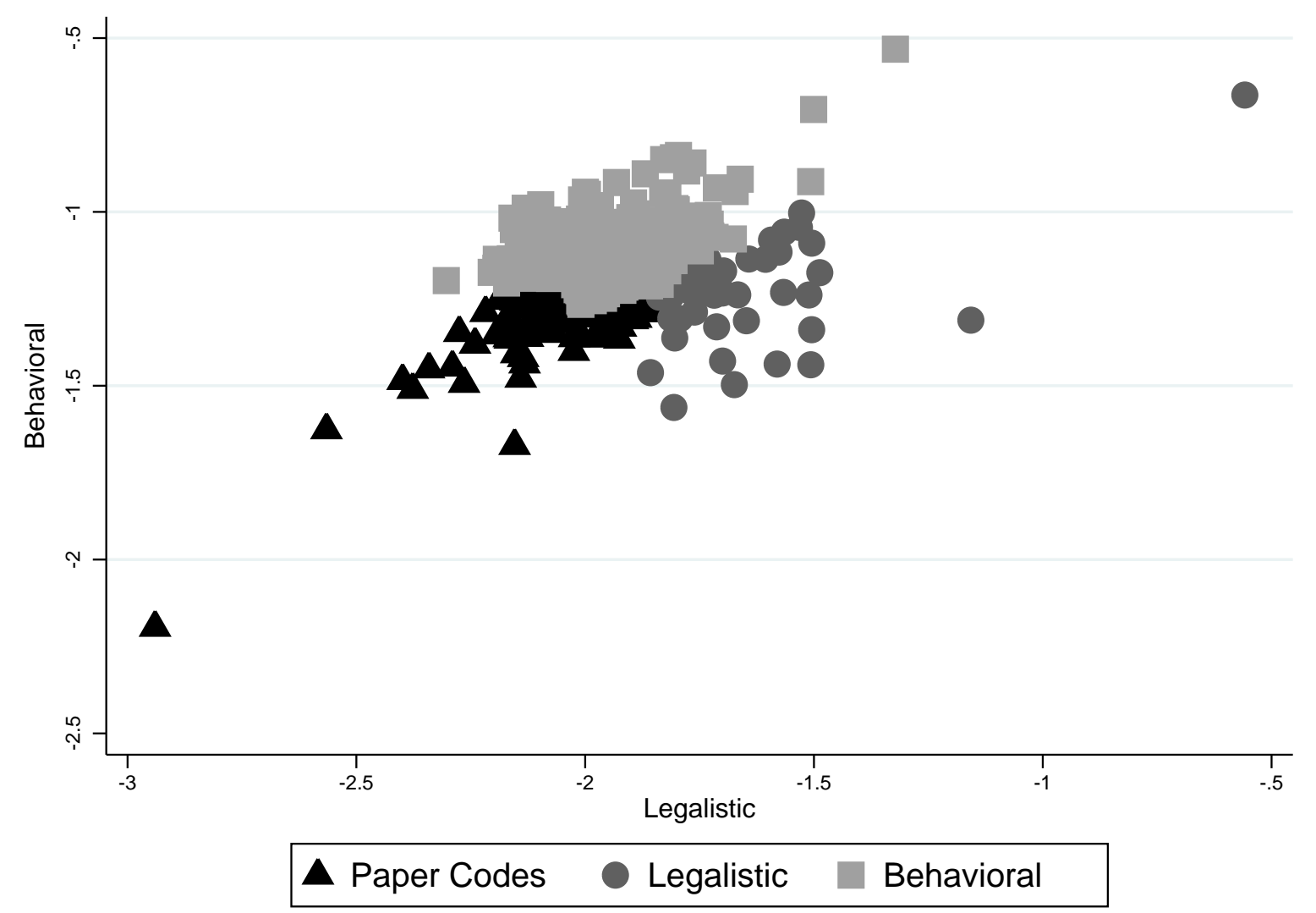

Figure 4 shows that there are indeed different clusters based on the legal and behavioral contents of codes: paper codes, which are clustered in the lower left-hand side of the graph; behavioral codes, situated in the upper left-hand side; and legal, placed at the right-hand side. We observe that hybrid codes, a theoretical construct we believe to exist, was not present in our sample data. Nonetheless, we conclude that our H1 hypothesis - the existence of different clusters based on a code's legal and behavioral content — is indeed corroborated by the data.

Given the main result, we now turn to the evaluation of its robustness. Firstly, we evaluate whether these same clusters hold when we use the relative and z-score transformed variables for behavioral and legal content (equations 3.3 to 3.6). 
Figure 5 - Plots of Z-Score and Relative Measure Clusters

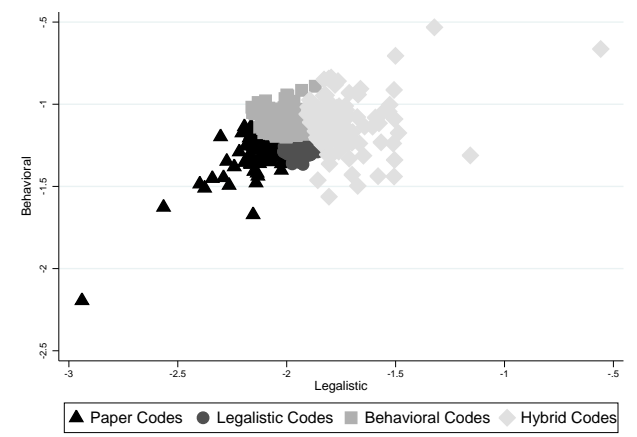

(a) Relative Measure

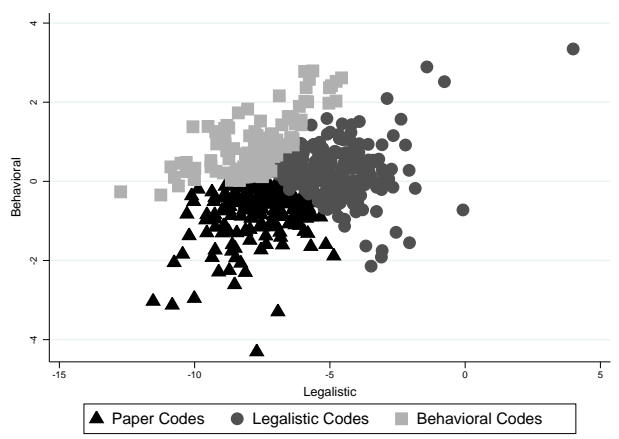

(b) Z-Score Measure

Figure 5 highlights that our three clusters are maintained, regardless of the measure. Although slight differences in clustering groups are observed, the general concept maintains the same: three distinct clusters, each with a defined balance of legal and behavioral words.

Turning to the distance metrics (and maintaining the ln of the content variable), we observe that the general behavior is still maintained: well-defined, theoretically meaningful clusters do emerge. Moreover, in some of the clusters our fourth category - the hybrid codes - indeed emerge at the some of the clustering analysis. Therefore, we again have strong evidence in support of our first hypothesis. Figures 6 highlights our discussions.

Figure 6 - Plots of Alternative Distance Variables Clusters

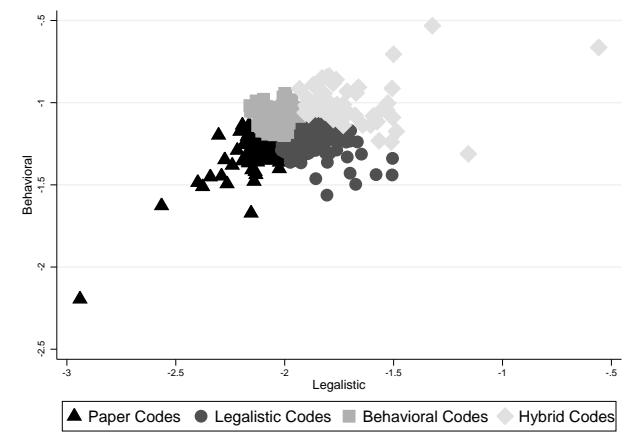

(a) LP2 Measure

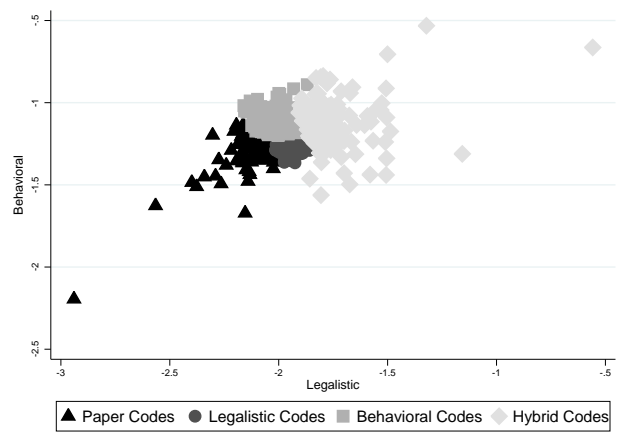

(b) L1 Measure

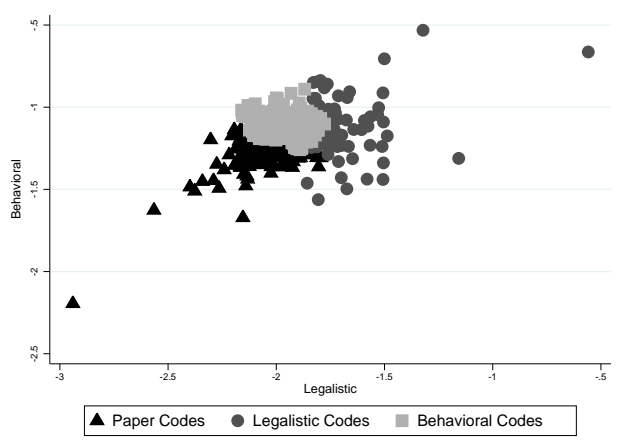

(c) L-Infinite Measure 
Finally, we can evaluate changing both parameters at the same time: the content variable and the measures of distance. Here, we also included a new variation of the code content: the raw percentage of each categorization. Again, no surprises: we find three or four meaningful clusters, regardless of the combination of parameters. Figures 7 to 9 illustrate our findings.

Figure 7 - Plots of Relative Measure and Alternative Distance Variables Clusters

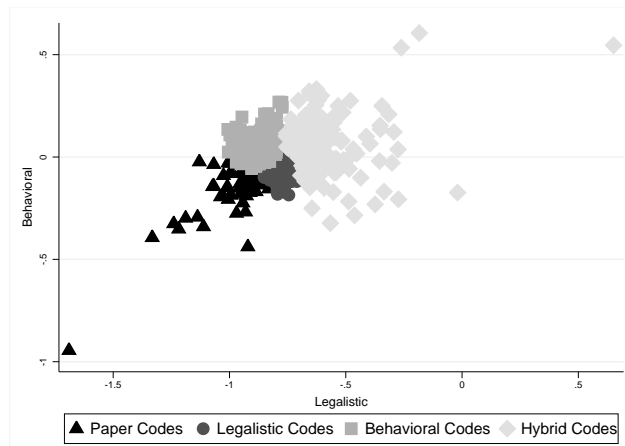

(a) L1 Measure

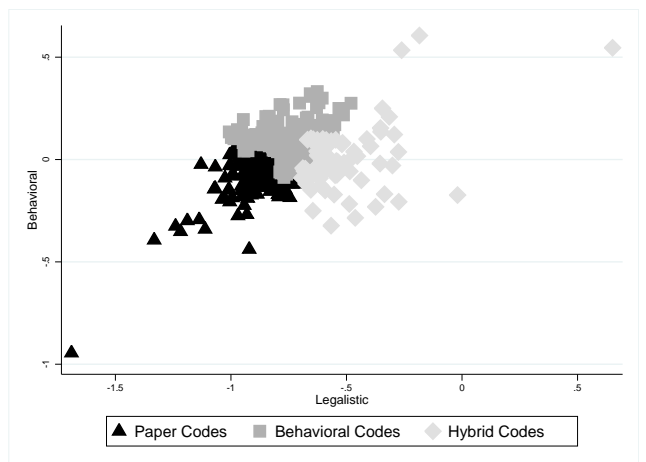

(c) L2-Squared Measure

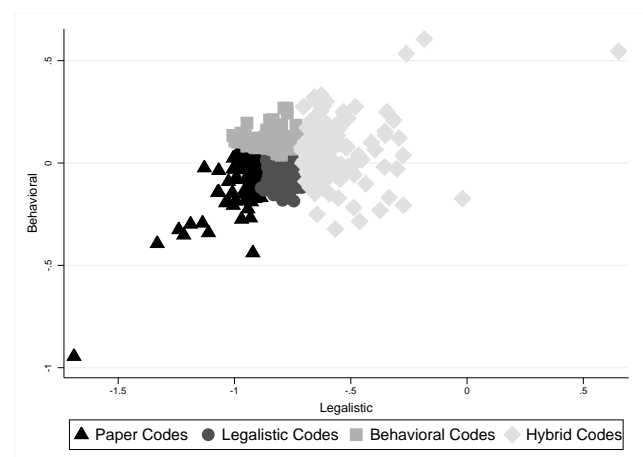

(b) L2 Measure

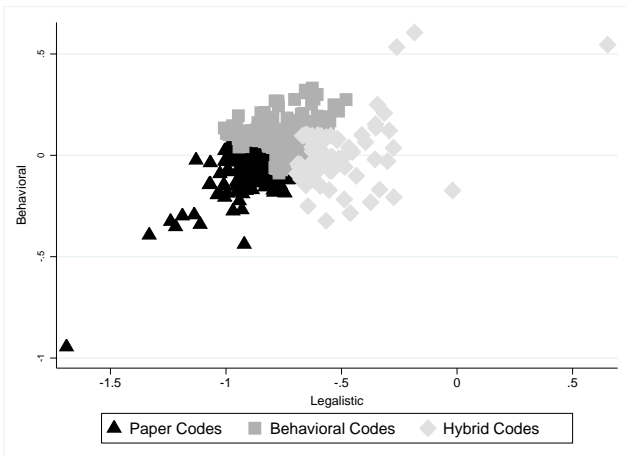

(d) LP2 Measure

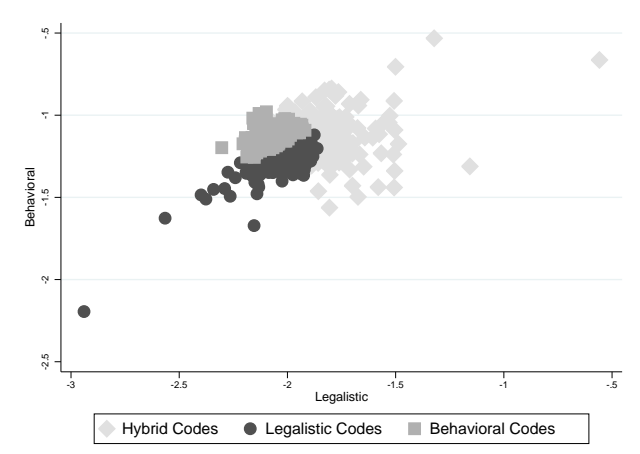

(e) L-Infinite Measure 
Figure 8 - Plots of Z-Score and Alternative Distance Variables Clusters

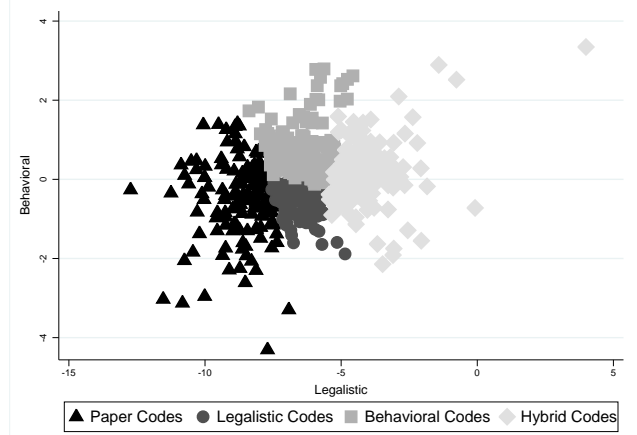

(a) L2-Squared Measure

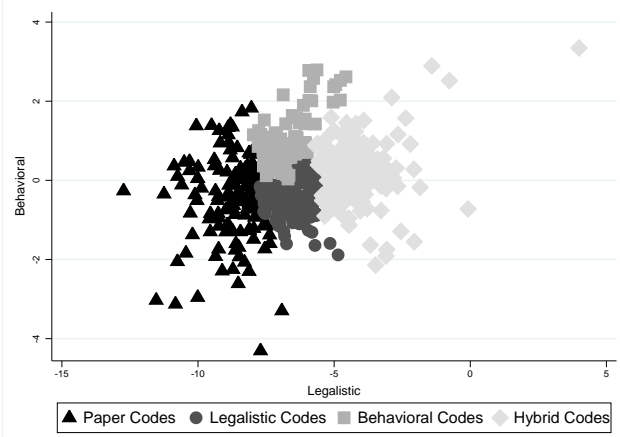

(b) L-Infinite Measure

Figure 9 - Plots of Raw Percentage and Alternative Distance Variables Clusters

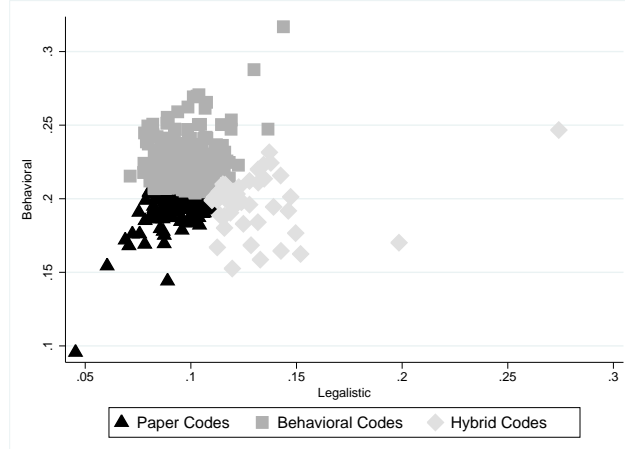

(a) LL2 Measure

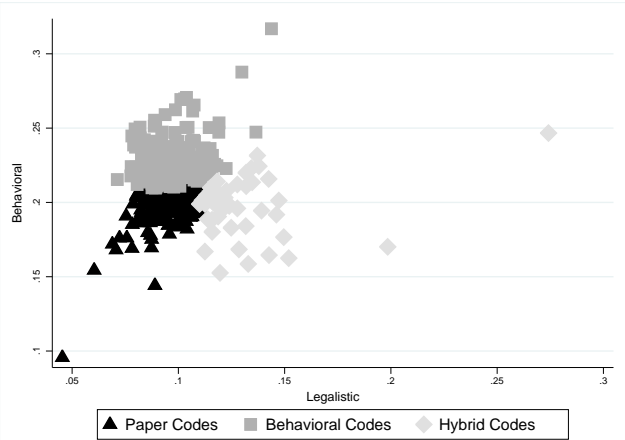

(b) L2-Squared Measure

From the previous analysis, it is clear that our theoretical constructs are consistently backed up by the clustering analysis. Our categorizations are meaningful, and no deviation is found no matter how we frame the analysis. Notwithstanding the fact that we do have this variation of three and four clusters depending on how the clustering is performed, we are confident that this result has shown itself to be robust and to have validity.

Now that we have found our constructs, we close this chapter and turn to the normative evaluation of a code's content effectiveness. As mentioned in this article, we will use for the regression analysis the granular variables, instead of relying on our clustering constructs for two reasons: (i) to have more degrees of freedom to perform our analysis; and (ii) to avoid any subjectivity discussions on our results to follow.

\subsection{REGRESSION ANALYSIS}

\subsubsection{Risk of Misbehavior}

After affirmatively answering our H1, we now turn to the discussion on the code's content effectiveness. Given that there are differences in how codes are structured - and 
we tested it with a wide variety of measures - what difference does it truly make? To answer this question, we turn to a view on how a code's content influences effectiveness.

To test our hypothesis of code effectiveness based on a code's content, we use the three severity levels of ESG issues from the RepRisk database. In the same fashion as in our clustering analysis, we then proceed to test different models, with transformed variables on the code's content side (e.g., relative and z-score transformations), as well as on the dependent variable side (i.e., UNGC violations).

By testing using ZINB and ZIP, we conclude by observing Akaike's information criterion (AIC) and Bayesian information criterion (BIC) that ZIP is preferred when compared to the ZINB model. To keep our results concise - and given that the results do not alter in a major way using ZINB - we proceed by using ZIP regressions.

Tables 14 to 16 highlight the models used to perform the regression analysis. On each regression, each pairwise model (i.e., (1) and (2), (3) and (4), and (5) and (6)) have the same regression parameters. Models (2), (4), and (6) use the Delaware dummy variable to estimate the variant-covariant matrix corresponding to the parameter estimates. Models (1), (3), and (5), on the other hand, use the standard robust estimator of variance. Finally, models (3) to (6) are variations using the transformed variables of the code's content, and therefore capture industry-specific effects.

Table 14 - Zero-Inflated Model with High Severity ESG Issues

\begin{tabular}{|c|c|c|c|c|c|c|c|c|c|c|c|c|}
\hline \multirow[b]{2}{*}{ VARIABLES } & \multicolumn{2}{|c|}{ (1) } & \multicolumn{2}{|c|}{ (2) } & \multicolumn{2}{|c|}{ (3) } & \multicolumn{2}{|c|}{ (4) } & \multicolumn{2}{|c|}{ (5) } & \multicolumn{2}{|c|}{ (6) } \\
\hline & Poisson & Inflated & Poisson & Inflated & Poisson & Inflated & Poisson & Inflated & Poisson & Inflated & Poisson & Inflated \\
\hline $\ln L C$ & $5.124^{* * *}$ & 9.781 & $5.124^{* * *}$ & 9.781 & & & & & & & & \\
\hline $\ln B C$ & $\begin{array}{r}(0.378) \\
-11.14^{* * *}\end{array}$ & $\begin{array}{c}(8.021) \\
-6.763\end{array}$ & $\begin{array}{r}(0.215) \\
-11.14^{* * *}\end{array}$ & $\begin{array}{r}(12.33) \\
-6.763\end{array}$ & & & & & & & & \\
\hline$R_{1}$ & $(3.320)$ & (5.723) & (1.178) & $(9.927)$ & & & & & & & & \\
\hline $\ln \frac{\ln L C}{2}$ & & & & & $\begin{array}{r}5.936 \cdots 14 \\
(0.614)\end{array}$ & $\begin{array}{l}7.904 \\
(9.552)\end{array}$ & $\begin{array}{r}5.936 \text { * } \\
(0.184)\end{array}$ & $\begin{array}{l}(1.904 \\
(14.34)\end{array}$ & & & & \\
\hline$R_{\ln B C}$ & & & & & $\begin{array}{r}-10.20^{* * * *} \\
(2.813)\end{array}$ & $\begin{array}{r}-6.460 \\
(6.200)\end{array}$ & $\begin{array}{r}-10.20^{* * *} * \\
(0.257)\end{array}$ & $\begin{array}{r}-6.460 \\
(11.17)\end{array}$ & & & & \\
\hline$Z_{\ln L C}$ & & & & & & & & & $0.507^{* * *}$ & 0.117 & $0.507^{* * *}$ & 0.117 \\
\hline$Z_{\ln B C}$ & & & & & & & & & $-0.819^{* *}$ & $\begin{array}{r}-0.0376 \\
\end{array}$ & $-0.819^{* * *}$ & $\begin{array}{l}(0.003) \\
-0.0376 \\
\end{array}$ \\
\hline Size & $0.441^{* * *}$ & $-1.066 * * *$ & $0.441 * * *$ & $-1.066^{* * * *}$ & $0.375^{* * *}$ & $-1.073^{* * *}$ & $0.375^{* * * *}$ & $-1.073^{* * *}$ & $\begin{array}{r}(0.391) \\
1.135^{* * * *}\end{array}$ & $\begin{array}{r}(0.269) \\
-0.691^{*}\end{array}$ & $\begin{array}{r}(0.145) \\
1.135^{* * *}\end{array}$ & $\begin{array}{l}(0.318) \\
-0.691^{*}\end{array}$ \\
\hline & $(0.0765)$ & $\begin{array}{r}(0.402) \\
0 . * * *\end{array}$ & $(0.0334)$ & $\begin{array}{l}(0.273) \\
0 . * * *\end{array}$ & $(0.0878)$ & $\begin{array}{r}(0.413) \\
0 . * *\end{array}$ & $(0.0327)$ & $(0.265)$ & $(0.158)$ & $(0.406)$ & $(0.0619)$ & $(0.416)$ \\
\hline $\mathrm{ROA}$ & $16.34^{* * *}$ & $\begin{array}{r}-15.82^{* * * *} \\
(5.973)\end{array}$ & $16.34^{* * *}$ & $-15.82^{* * * *}$ & $16.30^{* * *}$ & $-16.96^{* * * *}$ & $16.30^{* * *}$ & $-16.96^{* * * *}$ & $37.01^{* * *}$ & $\begin{array}{r}-10.22 \\
(6605)\end{array}$ & $37.01^{* * *}$ & $\begin{array}{l}-10.22 \\
(8.760)\end{array}$ \\
\hline Constant & $\begin{array}{l}-21.56^{* * *} \\
-\end{array}$ & $15.46^{* *}$ & $-21.566^{* * * *}$ & $15.46^{*}$ & $\begin{array}{r}(1.096) \\
-12.63 * * *\end{array}$ & $\begin{array}{l}\text { (b.1919) } \\
12.29^{*}\end{array}$ & $\begin{array}{r}(0.0340) \\
-12.63 * * *\end{array}$ & $\begin{array}{r}(2.508) \\
12.29\end{array}$ & $\begin{array}{r}(81.69 * * 2) \\
-21.69\end{array}$ & $\begin{array}{l}(6.605) \\
11.40^{*}\end{array}$ & $\begin{array}{r}(4.015) \\
-21.69^{* * *}\end{array}$ & $\begin{array}{r}(8.760) \\
11.40\end{array}$ \\
\hline & $(5.895)$ & $(6.450)$ & $(2.257)$ & (8.141) & $(1.634)$ & $(7.372)$ & $(0.198)$ & (11.95) & (5.448) & (6.144) & $(2.255)$ & $(8.052)$ \\
\hline Delaware & No & No & Yes & Yes & No & No & Yes & Yes & No & No & Yes & Yes \\
\hline Observations & 493 & 493 & 493 & 493 & 493 & 493 & 493 & 493 & 493 & 493 & 493 & 493 \\
\hline
\end{tabular}


Table 15 - Zero-Inflated Model with Medium Severity ESG Issues

\begin{tabular}{|c|c|c|c|c|c|c|c|c|c|c|c|c|}
\hline \multirow[b]{2}{*}{ VARIABLES } & \multicolumn{2}{|c|}{ (1) } & \multicolumn{2}{|c|}{ (2) } & \multicolumn{2}{|c|}{ (3) } & \multicolumn{2}{|c|}{ (4) } & \multicolumn{2}{|c|}{ (5) } & \multicolumn{2}{|c|}{ (6) } \\
\hline & Poisson & Inflated & Poisson & Inflated & Poisson & Inflated & Poisson & Inflated & Poisson & Inflated & Poisson & Inflated \\
\hline $\ln L C$ & 0.426 & 1.674 & 0.426 & $1.674^{* * *}$ & & & & & & & & \\
\hline & (1.316) & $(1.072)$ & (1.599) & $(0.0675)$ & & & & & & & & \\
\hline $\ln B C$ & $\begin{array}{l}-0.414 \\
(0.953)\end{array}$ & $\begin{array}{r}-0.0272 \\
(0.797)\end{array}$ & $\begin{array}{r}-0.414 \\
(0.483)\end{array}$ & $\begin{array}{r}-0.0272 \\
(0.141)\end{array}$ & & & & & & & & \\
\hline$R \_\ln L C$ & & & & & 0.913 & 1.741 & 0.913 & $1.741^{* * * *}$ & & & & \\
\hline & & & & & (1.515) & $\begin{array}{l}(1.109) \\
\text { (1. }\end{array}$ & (1.705) & $(0.157)$ & & & & \\
\hline$R \_l n B C$ & & & & & $\begin{array}{r}-0.200 \\
(0.853)\end{array}$ & $\begin{array}{c}-0.0744 \\
(0.784)\end{array}$ & $\begin{array}{r}-0.200 \\
(0.531)\end{array}$ & $\begin{array}{r}-0.0744 \\
(0.143)\end{array}$ & & & & \\
\hline$Z \_\ln L C$ & & & & & & & & & 0.111 & 0.155 & 0.111 & $0.155^{* * *}$ \\
\hline & & & & & & & & & $(0.164)$ & $(0.146)$ & $(0.233)$ & $(0.0107)$ \\
\hline$Z \_\ln B C$ & & & & & & & & & $\begin{array}{r}-0.0286 \\
(0.0608)\end{array}$ & $\begin{array}{r}0.0246 \\
0.0716\end{array}$ & $\begin{array}{l}-0.0286 \\
(0.202)\end{array}$ & 0.0246 \\
\hline Size & $0.378^{* * * *}$ & -0.142 & $0.378^{* * * *}$ & -0.142 & $0.388^{* * *}$ & -0.139 & $0.388^{* * *}$ & -0.139 & $0.392^{* * * *}$ & $\begin{array}{r}0.0 .139 \\
-0.139\end{array}$ & $0.392^{* *}$ & -0.139 \\
\hline & $(0.118)$ & $(0.0908)$ & $(0.132)$ & $(0.133)$ & $(0.125)$ & $(0.0903)$ & $(0.134)$ & $(0.132)$ & $(0.134)$ & $(0.0887)$ & $(0.156)$ & $(0.134)$ \\
\hline ROA & 2.635 & 0.898 & 2.635 & $0.898^{* * *}$ & 2.495 & 0.748 & 2.495 & $0.748^{* * *}$ & 2.655 & 0.568 & 2.655 & 0.568 \\
\hline & (3.141) & $(2.417)$ & $(3.879)$ & $(0.189)$ & $(2.947)$ & $(2.413)$ & $(3.456)$ & $(0.253)$ & $(2.960)$ & $(2.529)$ & $(3.560)$ & $(0.569)$ \\
\hline Constant & -1.004 & $5.086^{* * *}$ & $-1.004^{* *}$ & $5.086^{* * *}$ & -0.941 & $3.070^{* *}$ & -0.941 & $3.070^{* * *}$ & -1.032 & $3.286^{* * *}$ & -1.032 & $3.286^{*}$ \\
\hline & (1.605) & $(1.955)$ & $(0.502)$ & $(0.901)$ & $(1.802)$ & $(1.248)$ & $(1.875)$ & (1.136) & (1.652) & $(1.092)$ & (1.848) & (1.724) \\
\hline Delaware & No & No & Yes & Yes & No & No & Yes & Yes & No & No & Yes & Yes \\
\hline $\begin{array}{l}\text { Observations } \\
\text { Robust standard errors in parentheses } \\
* * * \mathrm{p}<0.01,{ }^{*} \mathrm{p}<0.05, * \mathrm{p}<0.1\end{array}$ & 493 & 493 & 493 & 493 & 493 & 493 & 493 & 493 & 493 & 493 & 493 & 493 \\
\hline
\end{tabular}

Table 16 - Zero-Inflated Model with Low Severity ESG Issues

\begin{tabular}{|c|c|c|c|c|c|c|c|c|c|c|c|c|}
\hline \multirow[b]{2}{*}{ VARIABLES } & \multicolumn{2}{|c|}{ (1) } & \multicolumn{2}{|c|}{ (2) } & \multicolumn{2}{|c|}{ (3) } & \multicolumn{2}{|c|}{ (4) } & \multicolumn{2}{|c|}{ (5) } & \multicolumn{2}{|c|}{ (6) } \\
\hline & Poisson & Inflated & Poisson & Inflated & Poisson & Inflated & Poisson & Inflated & Poisson & Inflated & Poisson & Inflated \\
\hline $\ln L C$ & $\begin{array}{r}0.314 \\
(1.386)\end{array}$ & $\begin{array}{r}0.411 \\
(1.027)\end{array}$ & $\begin{array}{r}0.314 \\
(1.548)\end{array}$ & $\begin{array}{r}0.411 \\
(1.319)\end{array}$ & & & & & & & & \\
\hline $\ln B C$ & $\begin{array}{r}0.833 \\
(1.331)\end{array}$ & $\begin{array}{r}0.720 \\
(0.807)\end{array}$ & $\begin{array}{r}0.833^{* * * *} \\
(0.182)\end{array}$ & $\begin{array}{r}0.720 \\
(0.762)\end{array}$ & & & & & & & & \\
\hline$R \_\ln L C$ & & & & & $\begin{array}{r}0.753 \\
(1.535)\end{array}$ & $\begin{array}{r}0.586 \\
(1058\end{array}$ & $\begin{array}{r}0.753 \\
(1519)\end{array}$ & $\begin{array}{r}0.586 \\
\text { r }\end{array}$ & & & & \\
\hline$R \_\ln B C$ & & & & & $\begin{array}{r}1.037 \\
(1.210)\end{array}$ & $\begin{array}{r}0.737 \\
(0.798)\end{array}$ & $\begin{array}{r}1.037^{* * * *} \\
(0.157)\end{array}$ & $\begin{array}{r}0.737 \\
(0.792)\end{array}$ & & & & \\
\hline$Z \_\ln L C$ & & & & & & & & & $\begin{array}{r}0.113 \\
(0.158)\end{array}$ & $\begin{array}{r}0.0658 \\
(0.131)\end{array}$ & $\begin{array}{r}0.113 \\
(0.199)\end{array}$ & $\begin{array}{c}0.0658 \\
(0.121)\end{array}$ \\
\hline$Z \_\ln B C$ & & & & & & & & & $\begin{array}{r}0.0391 \\
(0.0898)\end{array}$ & $\begin{array}{r}0.0791 \\
(0.0629)\end{array}$ & $\begin{array}{r}0.0391 \\
(0.0392)\end{array}$ & $\begin{array}{r}0.0791 \\
(0.0906)\end{array}$ \\
\hline Size & $\begin{array}{r}0.535^{* * *} \\
(0.123)\end{array}$ & $\begin{array}{r}0.0527 \\
(0.0900)\end{array}$ & $\begin{array}{r}0.535^{* * *} \\
(0.126)\end{array}$ & $\begin{array}{r}0.0527 \\
(0.101)\end{array}$ & $\begin{array}{r}0.545^{* * *} \\
(0.124)\end{array}$ & $\begin{array}{r}0.0538 \\
(0.0895)\end{array}$ & $\begin{array}{r}0.545^{* * *} \\
(0.116)\end{array}$ & $\begin{array}{r}0.0538 \\
(0.0999)\end{array}$ & $\begin{array}{r}0.540^{* * *} \\
(0.123)\end{array}$ & $\begin{array}{r}0.0663 \\
(0.0890)\end{array}$ & $\begin{array}{r}0.540^{* * *} \\
(0.110)\end{array}$ & $\begin{array}{r}0.0663 \\
(0.0906)\end{array}$ \\
\hline $\mathrm{ROA}$ & $\begin{array}{c}5.995^{* *} \\
(2.937)\end{array}$ & $\begin{array}{r}1.797 \\
(1.938)\end{array}$ & $\begin{array}{r}5.995 \\
(4.244)\end{array}$ & $\begin{array}{r}1.797^{* * * *} \\
(0.611)\end{array}$ & $\begin{array}{c}5.673^{* *} \\
(2.724)\end{array}$ & $\begin{array}{r}1.731 \\
(1.932)\end{array}$ & $\begin{array}{r}5.673 \\
(3.764)\end{array}$ & $\begin{array}{r}1.731^{* * * *}(0.586)\end{array}$ & $\begin{array}{c}5.557^{* *} \\
(2.749)\end{array}$ & $\begin{array}{r}1.236 \\
(2.008)\end{array}$ & $\begin{array}{c}5.557^{*} \\
(3.303)\end{array}$ & $\begin{array}{r}1.236 \\
(1.081)\end{array}$ \\
\hline Constant & $\begin{array}{r}0.114 \\
(23066\end{array}$ & $\begin{array}{r}2.744 \\
\end{array}$ & $\begin{array}{r}0.114 \\
(0.850)\end{array}$ & $\begin{array}{r}2.744^{* * * *} \\
(0.862)\end{array}$ & $\begin{array}{r}-1.179 \\
\end{array}$ & $\begin{array}{r}1.411 \\
(1204\end{array}$ & $\begin{array}{r}-1.179 \\
(1.096)\end{array}$ & $\begin{array}{l}1.411 \\
\end{array}$ & $\begin{array}{r}-1.664 \\
(1.666\end{array}$ & $\begin{array}{r}1.252 \\
(1.025\end{array}$ & $\begin{array}{c}-1.664^{*} \\
(0860)\end{array}$ & $\begin{array}{l}1.252 \\
1.445\end{array}$ \\
\hline Delaware & $\begin{array}{r}(2.306) \\
\text { No }\end{array}$ & $\begin{array}{r}(1.796) \\
\text { No }\end{array}$ & $\begin{array}{r}(0.850) \\
\text { Yes }\end{array}$ & $\begin{array}{r}(0.862) \\
\text { Yes }\end{array}$ & $\begin{array}{r}\text { (1.967) } \\
\text { No }\end{array}$ & $\begin{array}{r}(1.204) \\
\text { No }\end{array}$ & $\begin{array}{r}(1.096) \\
\text { Yes }\end{array}$ & $\begin{array}{r}(1.531) \\
\text { Yes }\end{array}$ & $\begin{array}{r}\text { (1.666) } \\
\text { No }\end{array}$ & $\begin{array}{r}(1.025) \\
\text { No }\end{array}$ & $\begin{array}{r}(0.860) \\
\text { Yes }\end{array}$ & $\begin{array}{r}(1.445) \\
\text { Yes }\end{array}$ \\
\hline $\begin{array}{l}\text { Observations } \\
\text { Robust standar } \\
*_{* * *}<<0.01,{ }^{* *}\end{array}$ & 493 & 493 & 493 & 493 & 493 & 493 & 493 & 493 & 493 & 493 & 493 & 493 \\
\hline
\end{tabular}

The results are precise and consistent with our previous theoretical assumptions:

- A bigger proportion of behavioral content is linked with a reduction in the number of ESG issues events. This behavior is consistent in all three levels of severity we evaluated. For example, we observe that, ceteris paribus, on average a $10 \%$ increase in the behavioral content is linked to a decrease of approximately 1.2 high-severity ESG event within the three years considered. What these results entitle is that companies that recognize in their compliance policies behavioral topics are less prone to engage in activities that are translated into a less effective compliance policy

- A bigger proportion of legal content is linked with an increase in the number of ESG issues events. While the behavioral content seems to be negatively correlated with code effectiveness, legal content works in the opposite direction. For instance, on average, a $10 \%$ increase in the legal content is linked to an increase of approximately 0.6 high-severity ESG issues events in the period (again, ceteris paribus. We also note that the behavioral content effect is twice as strong as the legal effect. 
- Industry-effects are present and have significant effects on our analysis. We observe the differences between the ln and transformed variables, and that statistical significance is more prominent using the relative and z-score variables. Also, it is essential to mention that the models point in the same direction: behavioral content linked with a smaller probability of ESG issues; legal content the other way.

- State of incorporation is significant and provides smaller standard deviations. As we would also expect, whether the company has its state of incorporation in Delaware or not seems to reduce the standard errors, which provides a higher statistical significance to the regression results. Again, it does not come as a surprise, as Delaware has its intricate institutional settings, which most assuredly influence code effectiveness.

- Size and ROA are significant control variables with regards to code effectiveness. The size of the company and its ROA are correlated with the number of ESG issues in almost every regression model. However, results have to be dissected more carefully as they seem to invert their effect when considering the state of incorporation control variable. We understand that bigger companies might face imminent risks with a higher frequency when compared to smaller ones; however, bigger companies also have more resources to effectively promote changes in their organizational structure, which can promote less risky behavior. Also, smaller companies in our samples are prominent, especially in the financial sector, with mutual and insurance funds, again companies that tend to have a more pronounced risk behavior.

Turning to the evaluation of UNGC violations, we do not have a sample size that allows us to analyze high severity impact violations. Therefore, we keep our analysis with medium and low severity cases. Once again — adding to the robustness of our results the same general guidelines maintain, albeit with less statistically significant results in some regressions. Once again, we observe that the models with statistical significance are usually those where industry-effects are accounted for. Tables 17 and 18 summarizes our regression discussions. 
Table 17 - Zero-Inflated Model with Medium Severity UNGC Violations

\begin{tabular}{|c|c|c|c|c|c|c|c|c|c|c|c|c|}
\hline \multirow[b]{2}{*}{ VARIABLES } & \multicolumn{2}{|c|}{ (1) } & \multicolumn{2}{|c|}{ (2) } & \multicolumn{2}{|c|}{ (3) } & \multicolumn{2}{|c|}{ (4) } & \multicolumn{2}{|c|}{ (5) } & \multicolumn{2}{|c|}{ (6) } \\
\hline & Poisson & Inflated & Poisson & Inflated & Poisson & Inflated & Poisson & Inflated & Poisson & Inflated & Poisson & Inflated \\
\hline $\ln L C$ & 0.241 & $1.790^{*}$ & 0.241 & $1.790^{* * *}$ & & & & & & & & \\
\hline $\ln B C$ & $\begin{array}{l}0.980) \\
-0.417\end{array}$ & $\begin{array}{r}(0.934) \\
-0.335\end{array}$ & $\begin{array}{l}(0.183) \\
-0.417\end{array}$ & $\begin{array}{l}(0.0740) \\
-0.335^{*}\end{array}$ & & & & & & & & \\
\hline$R \_\ln L C$ & $(0.789)$ & $(0.678)$ & $(0.503)$ & $(0.191)$ & 0.834 & $1.648^{*}$ & $0.834^{* * *}$ & $1.648^{* * *}$ & & & & \\
\hline & & & & & $(1.173)$ & $(0.972)$ & $(0.000382)$ & $(0.419)$ & & & & \\
\hline$R \_\ln B C$ & & & & & $\begin{array}{r}-0.137 \\
(0.708)\end{array}$ & $\begin{array}{r}-0.439 \\
(0.667)\end{array}$ & $\begin{array}{r}-0.137 \\
(0.330)\end{array}$ & $\begin{array}{r}-0.439^{*} \\
(0.255)\end{array}$ & & & & \\
\hline$Z \_\ln L C$ & & & & & & & & & 0.0429 & 0.149 & 0.0429 & $0.149 * *$ \\
\hline$Z \_\ln B C$ & & & & & & & & & $\begin{array}{l}(0.136) \\
0.0240\end{array}$ & $\begin{array}{l}(0.122) \\
-0.0231\end{array}$ & $\left(\begin{array}{c}0.0863) \\
0.0240\end{array}\right.$ & 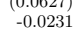 \\
\hline & & & & & & & & & $(0.0656)$ & $(0.0600)$ & $(0.0307)$ & $(0.0562)$ \\
\hline Size & $\begin{array}{c}0.205^{* *} \\
(0.0859)\end{array}$ & $\begin{array}{r}-0.281 * * * \\
(0.0824)\end{array}$ & $\begin{array}{r}0.205 * * * \\
(0.0775)\end{array}$ & $\begin{array}{r}-0.281^{* *} \\
(0.138)\end{array}$ & $\begin{array}{c}0.211^{* *} \\
(0.0887)\end{array}$ & $\begin{array}{r}-0.278^{* * *} \\
(0.0821)\end{array}$ & $\begin{array}{r}0.211^{* * *} \\
(0.0732)\end{array}$ & $\begin{array}{r}-0.278^{* *} \\
(0.139)\end{array}$ & $\begin{array}{c}0.209 * * \\
(0.0911)\end{array}$ & $\begin{array}{r}-0.283^{* * *} \\
(0.0811)\end{array}$ & $\begin{array}{c}0.209^{* *} \\
(0.0855)\end{array}$ & $\begin{aligned}-0.283^{* *} \\
(0.143)\end{aligned}$ \\
\hline $\mathrm{ROA}$ & 2.133 & 0.0457 & 2.133 & 0.0457 & 2.022 & -0.131 & 2.022 & -0.131 & 1.815 & -0.00301 & 1.815 & -0.00301 \\
\hline & $(2.662)$ & $(2.005)$ & $(2.430)$ & $(1.805)$ & $(2.568)$ & $(1.995)$ & $(2.410)$ & $(1.738)$ & $(2.350)$ & $(2.067)$ & $(2.742)$ & $(1.412)$ \\
\hline Constant & $\begin{array}{l}0.0855 \\
(1.380)\end{array}$ & $\begin{array}{r}5.597^{* * *} \\
(1.621)\end{array}$ & $\begin{array}{l}0.0855 \\
(0.182)\end{array}$ & $\begin{array}{r}5.597^{* * *} \\
(0.757)\end{array}$ & $\begin{array}{r}0.460 \\
(1.293)\end{array}$ & $\begin{array}{r}3.766^{* * *} \\
(1.074)\end{array}$ & $\begin{array}{r}0.460 \\
(0.720)\end{array}$ & $\begin{array}{r}3.766^{* * *} \\
(1.024)\end{array}$ & $\begin{array}{r}0.739 \\
(1.124)\end{array}$ & $\begin{array}{r}3.996 * * * \\
(0.974)\end{array}$ & $\begin{array}{r}0.739 \\
(1.318)\end{array}$ & $\begin{array}{l}3.996 * * \\
(1.647)\end{array}$ \\
\hline Delaware & No & No & Yes & Yes & No & No & Yes & Yes & No & No & Yes & Yes \\
\hline Observations & 493 & 493 & 493 & 493 & 493 & 493 & 493 & 493 & 493 & 493 & 493 & 493 \\
\hline $\begin{array}{l}\text { Robust standard errors in parentheses } \\
{ }_{* * *} \mathrm{p}<0.01, * * \mathrm{p}<0.05, * \mathrm{p}<0.1\end{array}$ & & & & & & & & & & & & \\
\hline
\end{tabular}

Table 18 - Zero-Inflated Model with Low Severity UNGC Violations

\begin{tabular}{|c|c|c|c|c|c|c|c|c|c|c|c|c|}
\hline \multirow[b]{2}{*}{ VARIABLES } & \multicolumn{2}{|c|}{ (1) } & \multicolumn{2}{|c|}{ (2) } & \multicolumn{2}{|c|}{ (3) } & \multicolumn{2}{|c|}{ (4) } & \multicolumn{2}{|c|}{ (5) } & \multicolumn{2}{|c|}{ (6) } \\
\hline & Poisson & Inflated & Poisson & Inflated & Poisson & Inflated & Poisson & Inflated & Poisson & Inflated & Poisson & Inflated \\
\hline $\ln L C$ & $\begin{array}{r}0.329 \\
\end{array}$ & 1.479* & 0.329 & $1.479^{* *}$ & & & & & & & & \\
\hline $\ln B C$ & 0.257 & $\begin{array}{l}-0.265 \\
-\end{array}$ & $0.257^{* *}$ & $\begin{array}{r}(0.713) \\
-0.265\end{array}$ & & & & & & & & \\
\hline & $(0.695)$ & $(0.658)$ & $(0.122)$ & $(0.459)$ & & & & & & & & \\
\hline$R \_\ln L C$ & & & & & $\begin{array}{r}0.876 \\
(0.960)\end{array}$ & $\begin{array}{r}1.405 \\
(0.924)\end{array}$ & $\begin{array}{r}0.876^{* * * *} \\
(0.0580)\end{array}$ & $\begin{array}{r}1.405 \\
(0.952)\end{array}$ & & & & \\
\hline$R \_\ln B C$ & & & & & $\begin{array}{r}0.442 \\
(0.693)\end{array}$ & $\begin{array}{r}-0.338 \\
(0.641)\end{array}$ & $\begin{array}{r}0.442 \\
(0.287)\end{array}$ & $\begin{array}{r}-0.338 \\
(0.410)\end{array}$ & & & & \\
\hline$Z \_\ln L C$ & & & & & & & & & 0.103 & 0.146 & 0.103 & 0.146 \\
\hline & & & & & & & & & $(0.117)$ & $(0.114)$ & $(0.0657)$ & $(0.104)$ \\
\hline$Z \_\ln B C$ & & & & & & & & & $\begin{array}{r}0.0284 \\
(0.059)\end{array}$ & -0.0170 & $\begin{array}{r}0.0284 \\
(0.502)\end{array}$ & $\begin{array}{r}-0.0170 \\
(0.068)\end{array}$ \\
\hline Size & $0.415^{* * *}$ & $-0.159^{* *}$ & $0.415^{* * *}$ & -0.159 & $0.421^{* * *}$ & $-0.157^{* *}$ & $0.421^{* * *}$ & -0.157 & $0.422^{* * *}$ & $-0.161^{* *}$ & $0.422^{* * *}$ & -0.161 \\
\hline & $(0.0649)$ & $(0.0756)$ & $(0.0118)$ & $(0.108)$ & $(0.0665)$ & $(0.0754)$ & $(0.00238)$ & $(0.108)$ & $(0.0663)$ & $(0.0747)$ & $(0.00556)$ & $(0.104)$ \\
\hline ROA & $\begin{array}{c}4.672^{*} \\
(2.501)\end{array}$ & $\begin{array}{r}-0.900 \\
(1.892)\end{array}$ & $\begin{array}{r}4.672^{* * * *} \\
(0.0307\end{array}$ & $\begin{array}{r}-0.900 \\
(1.777)\end{array}$ & $\begin{array}{c}4.388^{*} \\
(2.386)\end{array}$ & $\begin{array}{r}-1.032 \\
(1.879)\end{array}$ & $\begin{array}{r}4.388^{* * * * *} \\
(0.0618)\end{array}$ & $\begin{array}{r}-1.032 \\
(1.727)\end{array}$ & $\begin{array}{l}4.264^{*} \\
(2.258)\end{array}$ & $\begin{array}{r}-0.919 \\
(1.929)\end{array}$ & $\begin{array}{r}4.264^{* * * *} \\
(0.236)\end{array}$ & $\begin{array}{r}-0.919 \\
(1.356)\end{array}$ \\
\hline Constant & -0.0778 & $3.924^{* * *}$ & $-0.0778^{* * *}$ & $3.924^{* * *}$ & -0.687 & $2.416^{* *}$ & $-0.687^{*}$ & $2.416^{*}$ & -0.837 & $2.598^{* * *}$ & -0.837 & $2.598^{* *}$ \\
\hline & (1.347) & $(1.467)$ & $(0.0279)$ & $(0.980)$ & $(0.886)$ & $(0.989)$ & $(0.367)$ & $(1.244)$ & $(0.822)$ & $(0.888)$ & $(0.510)$ & (1.302) \\
\hline Delaware & No & No & Yes & Yes & No & No & Yes & Yes & No & No & Yes & Yes \\
\hline Observations & 493 & 493 & 493 & 493 & 493 & 493 & 493 & 493 & 493 & 493 & 493 & 493 \\
\hline
\end{tabular}

From the results as mentioned above, we are confident that $\mathrm{H} 2$ is corroborated, showing robustness when (i) transforming the independent variables and (ii) changing the dependent variable. The results seem to point out that companies that embrace behavioral concepts are better suited to deal with organizational risks such as the number of ESG issues and UNGC violations. Once more, it is essential to point out that code content should not be window-dressing: it does not follow that by merely including more chapters related to behavioral concepts, a company might mitigate these organizational risks. Instead, codes should reflect a more intrinsic organizational arrangement, in which the decision-making creates these observed differences.

\subsubsection{Risk of Litigation}

Turning to measure code effectiveness as correlated with class action litigations, Table 19 highlights the model results without the Delaware dummy, and Table 20 considers this control variable. All remaining variables are the same for both models. 
Table 19 - OLS Regression Results Without Delaware Dummy

\begin{tabular}{|c|c|c|c|}
\hline \multirow[b]{2}{*}{ VARIABLES } & \multicolumn{3}{|c|}{ Regression Results } \\
\hline & $(1)$ & $(2)$ & (3) \\
\hline $\ln L C \_$rescaled & $\begin{array}{l}-0.176 \\
-0.120\end{array}$ & & \\
\hline $\ln L C \_$rescaled ${ }^{2}$ & $\begin{array}{r}0.022 \\
-0.015\end{array}$ & & \\
\hline $\ln B C \_$rescaled & $\begin{array}{r}0.192^{* *} \\
-0.097\end{array}$ & & \\
\hline $\ln B C \_$rescaled ${ }^{2}$ & $\begin{array}{l}-0.010 \\
-0.015\end{array}$ & & \\
\hline $\ln L C \_r e s c a l e d \ln B C \_$rescaled & $\begin{array}{l}-0.016 \\
-0.026\end{array}$ & & \\
\hline$R \_\ln L C \_$rescaled & & $\begin{array}{l}-0.193 \\
-0.117\end{array}$ & \\
\hline$R \_\ln L C \_r e s c a l e d^{2}$ & & $\begin{array}{r}0.0232^{*} \\
-0.014\end{array}$ & \\
\hline$R \_\ln B C \_$rescaled & & $\begin{array}{r}0.201^{* *} \\
-0.090\end{array}$ & \\
\hline$R \_\ln B C \_r e s c a l e d d^{2}$ & & $\begin{array}{l}-0.010 \\
-0.014\end{array}$ & \\
\hline$R \_l n L C \_r e s c a l e d R \_l n B C \_r e s c a l e d$ & & $\begin{array}{l}-0.018 \\
-0.024\end{array}$ & \\
\hline$Z \_\ln L C \_$rescaled & & & $\begin{array}{l}-0.023 \\
-0.074\end{array}$ \\
\hline$Z \_$ln $L C \_r e s c a l e d^{2}$ & & & $\begin{array}{r}0.003 \\
-0.005\end{array}$ \\
\hline$Z \_\ln B C \_$rescaled & & & $\begin{array}{l}-0.002 \\
-0.012\end{array}$ \\
\hline$Z \_$ln BC_rescaled ${ }^{2}$ & & & $\begin{array}{l}-0.000 \\
-0.000\end{array}$ \\
\hline$Z \_$ln $L C \_$rescaled $Z \_$ln $B C \_r e s c a l e d$ & & & $\begin{array}{r}0.000 \\
-0.002\end{array}$ \\
\hline Size & $\begin{array}{r}0.022 \\
-0.014\end{array}$ & $\begin{array}{r}0.022 \\
-0.014\end{array}$ & $\begin{array}{r}0.0229^{*} \\
-0.014\end{array}$ \\
\hline ROA & $\begin{array}{l}-0.351 \\
-0.241\end{array}$ & $\begin{array}{l}-0.348 \\
-0.241\end{array}$ & $\begin{array}{l}-0.371 \\
-0.240\end{array}$ \\
\hline Constant & $\begin{array}{r}0.171 \\
-0.305\end{array}$ & $\begin{array}{r}0.219 \\
-0.313\end{array}$ & $\begin{array}{r}0.130 \\
-0.338\end{array}$ \\
\hline Fixed Industry Effects & Yes & Yes & Yes \\
\hline $\begin{array}{l}\text { Observations } \\
\text { R-squared }\end{array}$ & $\begin{array}{r}479 \\
0.098\end{array}$ & $\begin{array}{r}479 \\
0.099\end{array}$ & $\begin{array}{r}479 \\
0.090\end{array}$ \\
\hline
\end{tabular}

Robust standard errors in parentheses.

Aerospace \& Defense as the reference group for industry sector. $* * * \mathrm{p}<0.01,{ }^{*} * \mathrm{p}<0.05, * \mathrm{p}<0.1$ 
Table 20 - OLS Regression Results With Delaware Dummy

\begin{tabular}{|c|c|c|c|}
\hline \multirow[b]{2}{*}{ VARIABLES } & \multicolumn{3}{|c|}{ Regression Results } \\
\hline & $(1)$ & $(2)$ & (3) \\
\hline \multirow[t]{2}{*}{$\ln L C_{\text {rescaled }}$} & -0.192 & & \\
\hline & -0.121 & & \\
\hline \multirow[t]{2}{*}{$\ln L C_{\text {rescaled }}^{2}$} & 0.023 & & \\
\hline & -0.015 & & \\
\hline \multirow[t]{2}{*}{$\ln B C_{\text {rescaled }}$} & $0.204^{* *}$ & & \\
\hline & -0.097 & & \\
\hline \multirow[t]{2}{*}{$\ln B C_{\text {rescaled }}^{2}$} & -0.010 & & \\
\hline & -0.014 & & \\
\hline \multirow[t]{2}{*}{$\ln L C_{\text {rescaled }} \ln B C_{\text {rescaled }}$} & -0.017 & & \\
\hline & -0.026 & & \\
\hline \multirow[t]{2}{*}{$R_{\ln L C \_ \text {rescaled }}$} & & $-0.207^{*}$ & \\
\hline & & -0.118 & \\
\hline \multirow{2}{*}{$R_{\ln L C_{\text {rescaled }}}^{2}$} & & $0.0244^{*}$ & \\
\hline & & -0.014 & \\
\hline \multirow[t]{2}{*}{$R_{\ln B C_{\text {rescaled }}}$} & & $0.211^{* *}$ & \\
\hline & & -0.090 & \\
\hline \multirow{2}{*}{$R_{\ln B C_{\text {rescaled }}}^{2}$} & & -0.011 & \\
\hline & & -0.013 & \\
\hline \multirow{2}{*}{$R_{\ln L C_{\text {rescaled }}} R_{\ln B C_{\text {rescaled }}}$} & & -0.018 & \\
\hline & & -0.024 & \\
\hline \multirow[t]{2}{*}{$Z_{\ln L C_{\text {rescaled }}}$} & & & -0.030 \\
\hline & & & -0.074 \\
\hline \multirow{2}{*}{$Z_{\ln L C_{\text {rescaled }}}^{2}$} & & & 0.004 \\
\hline & & & -0.005 \\
\hline \multirow[t]{2}{*}{$Z_{\ln B C_{\text {rescaled }}}$} & & & -0.002 \\
\hline & & & -0.012 \\
\hline \multirow{2}{*}{$Z_{\ln B C_{\text {rescaled }}}^{2}$} & & & -0.000 \\
\hline & & & -0.000 \\
\hline \multirow{2}{*}{$Z_{\ln L C_{\text {rescaled }}} Z_{\ln B C_{\text {rescaled }}}$} & & & 0.000 \\
\hline & & & -0.002 \\
\hline \multirow[t]{2}{*}{ Size } & $0.0236^{*}$ & $0.0236^{*}$ & $0.0238^{*}$ \\
\hline & -0.014 & -0.014 & -0.014 \\
\hline \multirow[t]{2}{*}{ ROA } & -0.318 & -0.315 & -0.345 \\
\hline & -0.241 & -0.241 & -0.239 \\
\hline \multirow[t]{2}{*}{ Delaware } & 0.031 & 0.031 & 0.026 \\
\hline & -0.029 & -0.029 & -0.029 \\
\hline \multirow[t]{2}{*}{ Constant } & 0.151 & 0.198 & 0.126 \\
\hline & -0.305 & -0.312 & -0.338 \\
\hline Fixed Industry Effects & Yes & Yes & Yes \\
\hline Observations & 479 & 479 & 479 \\
\hline R-squared & 0.099 & 0.101 & 0.092 \\
\hline
\end{tabular}

Robust standard errors in parentheses.

Aerospace \& Defense as the reference group for industry sector.

$* * * \mathrm{p}<0.01,{ }^{* *} \mathrm{p}<0.05, * \mathrm{p}<0.1$ 
We observe that, from the regression results above that the linear behavior content variable is significant and positively correlated with the number of class actions. However, when evaluation quadratic models, we must evaluate the marginal values, given the interactions of the quadratic and linear variables. Therefore, in addition to the regression results which are based on the mean value of the estimators, the matrix of predictive margins derived from the model also has important insights. Figure 10 highlights our analysis.

Figure 10 - Predictive Margins Plot of Class Action Likelihood

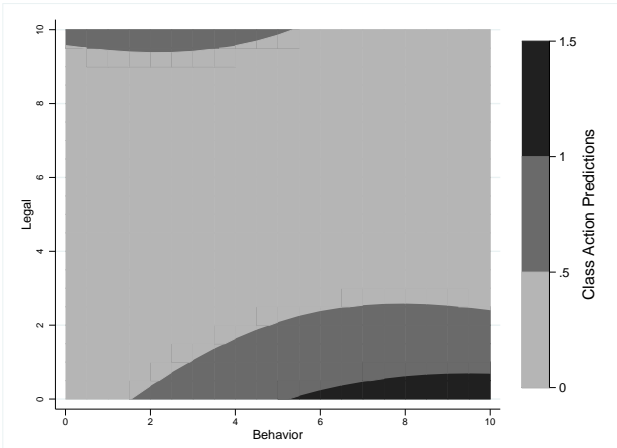

(a) $\ln L C$ and $\ln B C$

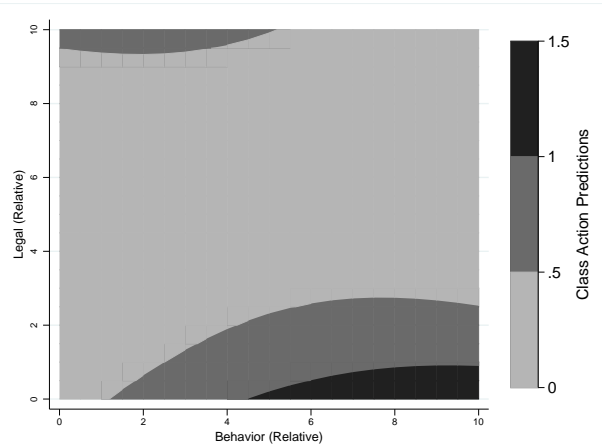

(b) Relative Transformation

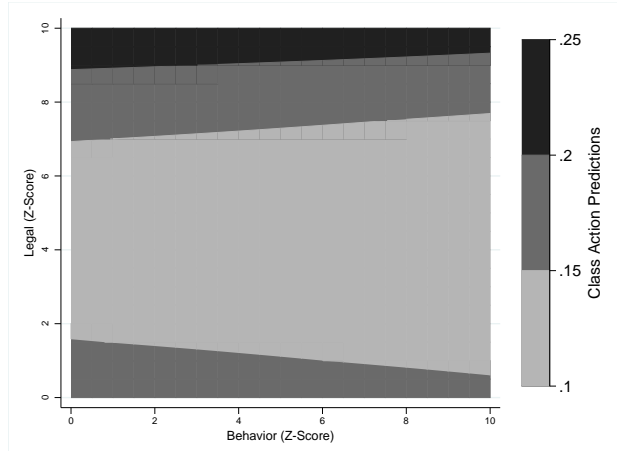

(c) Z-Score Transformation

The above figures provide a clearer picture of the interaction between the linear and quadratic variables of our model. The results show that legal content is generally linked with a lower predicted number of class actions. Only when legal code content become concentrated is that we observe a higher predicted value of class actions (i.e., codes strictly legal).

On the other hand, we observe that codes with a concentrated value of behavior content show a higher predicted number of class actions, even in more moderate content proportions. These results point to the fact that codes which rely heavily on behavioral content to the detriment of legal components are ill suited to deal with legal outcomes such as class action litigations. 


\section{DISCUSSION}

\subsection{CODES' CATEGORIES}

Our primary analysis shown in Figure 1 highlights three main clusters, according to our theoretical framework: (i) paper codes, which have a low percentage of behavioral and legal content; (ii) behavioral codes, with a high proportion of behavioral content and a small proportion of legal words; and (iii) legal codes, with a high ratio of legal content and a small percentage of behavioral terms. Paper codes, as already explained by Soltes, has as main objective being compliant with regulatory requirements, but with no real internal structure to create a reliable compliance system. These codes are comprised of few words that can be deemed to have a legal or behavioral objective and include around $30 \%$ of our sample data. Window-dressing codes are important detractors to robust compliance policies, given that they can foster counterarguments to the need and expenditure in formal ethical infrastructure (DOOREY, 2018).

Behavioral codes are the biggest group in our sample data and comprise around $60 \%$ of companies. These codes rely on behavioral ethics perspectives and have their content directed to psychological terms, aiming to influence ethical decision-making inside organizations. Their focus, therefore, is internal-looking when dealing with ethical decisionmaking of their employees, and outside-looking when versing about the consequences of a robust ethical system, typically relating to ESG topics such as labor equality, environmental commitments, among others. We cannot, however, forget that legal content is still twice as recurrent, on average, when compared to behavioral content. The fact that the code is categorized as behavior by no means indicates that the code has more behavioral content in absolute terms. It rather implies that the code has a balance of legal-behavior words that favor the categorization as a behavioral code.

Legal codes, on the other hand, comprise around $10 \%$ of our sample and are focused on being compliant with the regulatory environment. These codes are externallyfocused and have little guidance regarding employee behavior. As previously mentioned by (BONDY; MATTEN; MOON, 2004), these codes, when approaching employee behavior, usually are punitive in nature, stating the costs of potential misconduct. The code remains focused on explaining the efforts of the company towards legal provisions such as SOX, FCPA, data privacy guidelines, M\&A and antitrust standards, financial statements, records bookkeeping, among others.

Our main result did not find evidence of the hybrid cluster, which embraces both legal and behavioral prospects. However, we find that this code category is present when developing our transformed analysis with different dependent variables measurements and 
distance calculations. Therefore, we deem that the emergence and existence of hybrid codes are yet to be confirmed in future research. Another critical thing to mention is the code distribution, concentrated in the behavioral category. Our results point to the fact that companies - at least the largest ones - are beginning to look to behavioral aspects when modeling their compliance systems. Still, our result does not invalidate previous discussions on the importance of legal codes and their protectionist structure.

\subsection{CODE'S EFFECTIVENESS}

\subsubsection{Risk of Misbehavior}

Results seem to indicate a significant effect of code content on compliance effectiveness. Code content points towards the notion that more behavioral-prone organizations as measured by the code's content - are less likely to engage in risky events. This result proved to be robust both by severity level and changing how risk is measured.

The empirical results come as no surprise to us, given how codes and compliance policies have been constructed in the last thirty years, with a focus primarily on legal and regulatory aspects. Compliance systems are nowadays looking to the contribution of behavioral ethics, as highlighted in our clustering analysis, but the contribution is timid still. When faced with ethical dilemmas, codes that take into consideration the venues of the human mind when making decisions fare better in preventing misconduct from occurring. Acknowledging the process underlying ethical decision-making and incorporating it into formal compliance structures give an advantage for companies looking to increase their compliance effectiveness. Again, our results seem to indicate that when ethical guidelines are constructed from the bottom-up, understanding the organization's modus operandi and the limitations of human decision-making, they will outperform compliance systems created with a top-down approach.

The consequence of our analysis shows that, by studying codes and their structure, we can peek inside the organization's black box. How code is defined, its main contents and its language tells us about how the organization sees its internal and external stakeholders. Besides its objective of adhering to the regulations in place, it sometimes allows us to look at how the company positions itself in broader and more general societal topics. The results surface not from where the codes are equal, but where they differ and in which way.

Our results highlight that, /textitgiven current ethical practices and how codes are developed today, companies that engage in a more behaviorally-rich code should have reduced risks of misconduct only because it takes into consideration aspects of organizational behavior that more legal guidelines do not. However, as compliance policies change, the legal-behavioral balance can as well, which could also impact how one perceives the second hypothesis. When analyzing guidelines that are always evolving, a time-specific scenario shall be settled. 


\subsubsection{Risk of Litigation}

Behavioral-heavy codes are more likely to have class action incidents when compared to legal ones (and especially compared to hybrid codes). This result, then, might seem intriguing: how come a higher proportion of behavioral content be linked with a reduced risk profile while appearing to be correlated with a higher number of class actions?

It should not come as a surprise that legal content is better tuned to deal with legal outcomes. This is how formal ethical policies have been idealized since its birth, and legal topics have important features to navigate at the institutional environments big corporations are in. The results pinpoint the importance of having codes tuned to the existing regulatory frameworks.

The answer to this question lies precisely in how we measure outcomes. Companies are increasingly being faced with a plethora of risks that did not exist before, such as reputational risks linked with the high-velocity social media environment. Customer-facing companies can have their reputation - and, as a consequence, their market value severely impacted in a matter of hours, even if the rumor is far from being challenged in the courts. The speed and impact of social media risks are significant and only tangentially grasped by an outcome variable such as class action fillings.

As important as legal frameworks are, it is not ready to face is the risks and consequences that lie outside the legal realm and are rooted in the internet velocity era. These risks are better suited for companies that not only navigate the regulatory scene but also embrace insights such as behavioral ethics into their daily operations. Figure 11 summarizes our discussion.

\subsection{WHY SHOULD WE CARE ABOUT CODES?}

One might question why studying code effectiveness through codes matters. Cases such as Rana Plaza's justifiably create an atmosphere of distrust regarding how formal ethical systems are effectively able to influence organizational outcomes.

We ought to debunk this belief in two ways. First, we have to be careful not to fall into the availability bias trap. Evaluating compliance policies by only judging actions of misconduct that became widely known is an invitation to demote all the efforts of organizations that effectively could deter severe misconduct behavior. Given that these victories are decentralized and without much mediatic attention, they become a footnote compared to the famous behemoths of misconduct.

Second, evaluating how compliance systems influence effectiveness is as important as assessing how it impacts the system's outcomes. In today's society, we are going through a time where the harsher and most impactful actions are outside the legal court. Instead, they are on the social media judges, which can create market value fluctuations an order 
Figure 11 - Relation Between Total Outcomes and Legal Outcomes

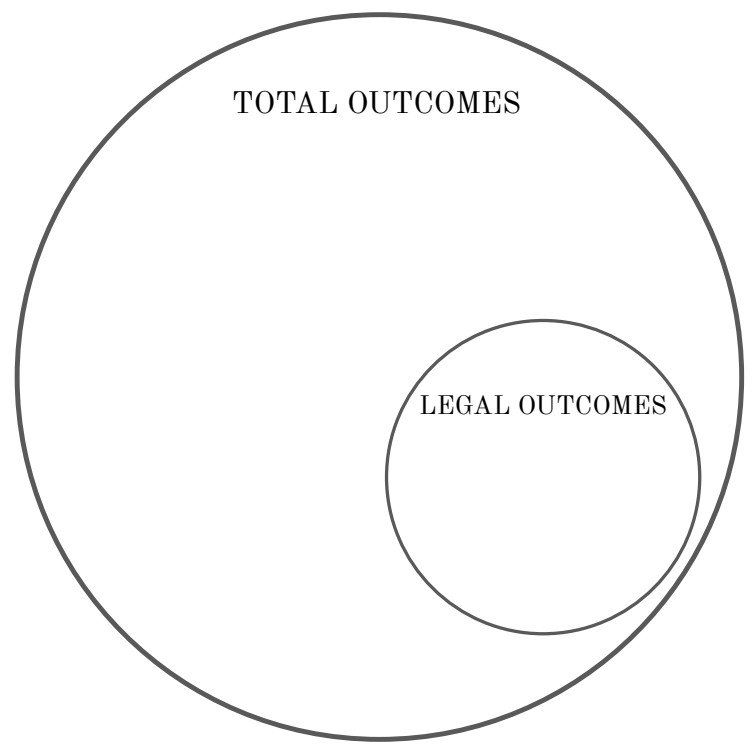

of magnitude higher than courts sometimes can.

These social media risks create an even greater incentive for companies to adopt indeed and back compliance guidelines, as they make yet another line of defense for companies to face the challenges that the internet era poses on how a company is seen and liked by the internet consumers. There is possibly no harder blow to a company's position than acts of misconduct that harms employees (e.g., Enron) or even the general society (e.g., Volkswagen). Companies' survival relies on their image to their ever-increasing list of stakeholders, and compliance effectiveness might offer the right remedy for that.

Finally, we observe that different metrics may produce different outcomes. For a compliance system to be effective, it should clearly state what the main goals of the system are, and what type of changes it tries to achieve. We understand that, for a complete compliance system analysis, a broader view of its effects on the enterprise should be considered. By narrowing the effects on specific and measurable items, inconclusive results are more likely to appear.

\subsection{FUTURE STUDIES}

This research line is at its beginning and, therefore, can profit immensely from efforts in many different directions. We propose some topics which might be of interest to develop further, although it is important to disclaim that this list is by no means exhaustive. 
- Usage of panel data with bigger sample sizes. Our research focused on a comprehensive set of companies. Nonetheless, given our dependent variables' infrequent occurrence, the analysis could only be performed by aggregating data and creating a cross-sectional dataset. We believe that by expanding the sample size, we can create a panel data analysis that can also include temporal dimensions in our content and empirical analysis.

- Understand the behavior before and after a risk or outcome. Once again, it is imperative to understand how a firm behaves - and change its compliance policies - before and after a risk or outcome occurs. How the code's structure and content change? Are there differences in organizational behavior if a company receives a positive or negative sentence? Many venues can be explored by studying how compliance restructuring occurs after important events, both at an organizational, industry, country, or global level.

- Impact of the frequency of code revisions. What does the frequency of code revisions might tell us about how a company understands its compliance policies? If these revisions are envisioned to accommodate major changes, how should we expect the organization to absorb its content, and what conclusion can be drawn about its compliance effectiveness? Again a thorough study of the content changes in terms of behavioral and legal terms can create a fruitful research line to be pursued.

- Expand our outcome variable to embrace other outcomes than legalbased ones. As we explained in section 5.3, our current corporate environment creates risks that surpass the legal realm. By constructing an outcome variable that also considers these supra-legal events, we ought to have a better and refined understanding of compliance effectiveness depending on the code content.

- Changes in code structure in Small and Medium Enterprises (SMEs). When studying the US's biggest 500 corporations, it is obvious that they have a considerable budget to spend to create their compliance policies. What changes when we change the lens to SMEs of family firms? Are there significant differences in code content and categorization? Given the importance of smaller companies in our economy, it is essential to check whether structural differences in code's content exist when comparing with big public corporations.

- Changes in code structure in different countries. Again, using the Fortune 500 companies was to mitigate any cross-country differences that could impact our analysis. However, it is also crucial to grasp how different cultures and institutional factors can create different legal-behavioral equilibriums and impact compliance programs' effectiveness. 
- Usage of machine learning models and natural language processing. Our research focused on using two different external dictionaries from accredited sources. That way, we mitigated any subjectivity, which could influence how the authors categorized different words and phrases. Another approach to be pursued is to use machine learning (ML) models and natural language processing to effectively train a model based on different documents (compliance policies or not). It would be interesting to see how these ML models would categorize each code and how they would differ from our external dictionary analysis. 


\section{CONCLUSION}

In the last twenty years, corporate scandals such as Loblaws, Enron, BP, Siemens, and Volkswagen have created a fertile ground for compliance policies, compliance programs, and codes in general. Albeit the enormous sums currently spent, the effectiveness of the systems and its main features remain a grey area for academics and practitioners in general.

We understand that systematic differences exist regarding how code is built and its language to communicate with internal and external stakeholders. These features tell us a lot about how the organization itself is structured and the considerations it makes related to ethical decision-making by its employees. We have aimed at deepening the discussion of codes in two ways: (i) by evaluating whether the differences between legal and behavioral content in codes could be validated using external dictionaries via clustering analysis; and (ii) whether the effectiveness of the code, measured by the company's risk exposure, could be correlated with a code's legal and behavioral content. To perform this, we used the 2017 Fortune 500 ranking, which is comprised of the biggest 500 US-headquartered companies by revenue.

Our results point towards the existence of four clusters: (i) paper codes, which have a low proportion of both legal and behavioral content, and it is used as a "check-the-box" document; (ii) legal codes, which have a high ratio of legal content and a low proportion of behavioral content, used mainly for hedging against risks inside the legal realm; (iii) behavioral codes, which have a high percentage of behavioral content and a low proportion of legal content, aimed at influencing ethical decision-making inside the organization; and (iv) hybrid codes, which have a high proportion of both legal and behavioral content.

Turning to our code effectiveness analysis, we find that companies with higher behavioral content have more effective compliance systems, as measured by the number of ESG issues and the number of UNGC violations, both with high, medium, and low severities. This results again adds to previous studies that found an over-reliance on compliance programs and compliance policies with a legal view in mind, to the detriment of thinking and structuring these policies to consider how ethical decision-making is genuinely made, with all its limitations. We believe that companies can benefit by bringing compliance policies back internally and create guidelines that have the power and robustness to deter misconduct at its core.

When considering effectiveness as measured by class action litigations, we find that behavioral content is linked with a likelihood of a higher number of class actions. Legal content is an important component to reduce risks related to litigation, and has been the main tool employed to promote shareholder protection since the emergence of corporate 
codes. However, companies face risks and challenges that are progressively outside the legal realm, and organizations also have to adapt to this new reality. By structuring its policies with the objective of only mitigating legal risks, companies can turn their back to a plethora of risks that can damage their reputation and market value as much as a traditional class action litigation. Social media's power and velocity create yet another incentive for companies to understand how their employees make decisions and how they can influence the company's image and stance. Here lies the power of behavioral ethics and its associated policies embedded into the more classical legal approach.

Lastly, this is a rich field that just has started to be explored. We propose many different avenues where the research line can be enhanced, from other data sources to distinct corporation's ownership and size, countries, and algorithms. We firmly believe that when assumptions of legal ethics and behavior findings diverge, incorporating the behavior ethics into the analysis of legal compliance may improve its explanatory and predictive power - and, eventually, its policy implications too. 


\section{BIBLIOGRAPHY}

AITCHISON, J. The statistical analysis of compositional data. Journal of the Royal Statistical Society: Series B (Methodological), Wiley Online Library, v. 44, n. 2, p. 139-160, 1982.

BABRI, M.; DAVIDSON, B.; HELIN, S. An updated inquiry into the study of corporate codes of ethics: 2005-2016. Journal of Business Ethics, Springer, p. 1-38, 2019.

BAKKER, F. G. de; RASCHE, A.; PONTE, S. Multi-stakeholder initiatives on sustainability: A cross-disciplinary review and research agenda for business ethics.

Business Ethics Quarterly, Cambridge University Press, v. 29, n. 3, p. 343-383, 2019.

BASINGER, S. J.; CANN, D. M.; ENSLEY, M. J. Voter response to congressional campaigns: new techniques for analyzing aggregate electoral behavior. Public Choice, Springer, v. 150, n. 3-4, p. 771-792, 2012.

BAZERMAN, M. H.; GINO, F. Behavioral ethics: Toward a deeper understanding of moral judgment and dishonesty. Annual Review of Law and Social Science, Annual Reviews, v. 8, p. 85-104, 2012.

BAZERMAN, M. H.; SEZER, O. Bounded awareness: Implications for ethical decision making. Organizational Behavior and Human Decision Processes, Elsevier, v. 136 , p. $95-105,2016$.

BAZERMAN, M. H.; TENBRUNSEL, A. E. Ethical breakdowns. Harvard Business Review, v. 89, n. 4, p. 58-65, 2011.

BECKER, G. S. Crime and punishment: An economic approach. In: The economic dimensions of crime. [S.l.]: Springer, 1968. p. 13-68.

. Nobel lecture: The economic way of looking at behavior. Journal of political economy, The University of Chicago Press, v. 101, n. 3, p. 385-409, 1993.

BONDY, K.; MATTEN, D.; MOON, J. The adoption of voluntary codes of conduct in mncs: A three-country comparative study. Business and Society Review, Blackwell Publishing, Ltd. Oxford, UK, v. 109, n. 4, p. 449-477, 2004.

CALDERÓN-CUADRADO, R. et al. "ethics hotlines" in transnational companies: A comparative study. Journal of business ethics, Springer, v. 88, n. 1, p. 199-210, 2009.

CALDERÓN, R.; FERRERO, I.; REDIN, D. M. Ethical codes and corporate responsibility of the most admired companies of the world: Toward a third generation ethics? Business and Politics, Cambridge University Press, v. 14, n. 4, p. 1-24, 2012.

CANARY, H. E.; JENNINGS, M. M. Principles and influence in codes of ethics: A centering resonance analysis comparing pre-and post-sarbanes-oxley codes of ethics. Journal of Business Ethics, Springer, v. 80, n. 2, p. 263-278, 2008.

CHOWDHURY, R. The rana plaza disaster and the complicit behavior of elite ngos. Organization, SAGE Publications Sage UK: London, England, v. 24, n. 6, p. 938-949, 2017. 
CRAFT, J. L. A review of the empirical ethical decision-making literature: 2004-2011. Journal of business ethics, Springer, v. 117, n. 2, p. 221-259, 2013.

CRESSEY, D. R.; MOORE, C. A. Managerial values and corporate codes of ethics. California Management Review, SAGE Publications Sage CA: Los Angeles, CA, v. 25, n. 4, p. 53-77, 1983.

DOOREY, D. J. Rana plaza, loblaw, and the disconnect between legal formality and corporate social responsibility. Social Science Research Network 3265826, p. 1-47, 2018.

ECONOMIST, T. The past decade has brought a compliance boom in banking. 2019. Disponível em: <https://www.economist.com/finance-and-economics/2019/05/02/ the-past-decade-has-brought-a-compliance-boom-in-banking $>$.

EVERITT, B. S. et al. Cluster Analysis. [S.l.]: John Wiley Sons, 2011. ISBN 978-0-470-74991-3.

FORD, R. C.; RICHARDSON, W. D. Ethical decision making: A review of the empirical literature. Journal of Business Ethics, Springer, v. 13, n. 3, p. 205-221, 1994.

FORSTER, M.; LOUGHRAN, T.; MCDONALD, B. Commonality in codes of ethics. Journal of Business Ethics, Springer, v. 90, n. 2, p. 129-139, 2009.

FRY, J. M.; FRY, T. R.; MCLAREN, K. R. Compositional data analysis and zeros in micro data. Applied Economics, Taylor \& Francis, v. 32, n. 8, p. 953-959, 2000.

GRIMMER, J.; KING, G. General purpose computer-assisted clustering and conceptualization. Proceedings of the National Academy of Sciences of the United States of America, v. 108, n. 7, p. 2643-2650, 2011.

GRINSTEIN, Y.; ROSSI, S. Good monitoring, bad monitoring. Review of Finance, Oxford University Press, v. 20, n. 5, p. 1719-1768, 2016.

HAIR, J. F. Multivariate data analysis: An overview. International encyclopedia of statistical science, Springer, p. 904-907, 2011.

HAUGH, T. Nudging corporate compliance. 2017.

HOLDER-WEBB, L.; COHEN, J. The cut and paste society: Isomorphism in codes of ethics. Journal of Business Ethics, Springer, v. 107, n. 4, p. 485-509, 2012.

IV, R. A. The delaware trap: an empirical analysis of incorporation decisions. S. Cal. L. Rev., HeinOnline, v. 91, p. 657, 2017.

KAHNEMAN, D. Thinking, fast and slow. [S.l.]: Macmillan, 2011.

KAPTEIN, M. Business codes of multinational firms: what do they say? Journal of Business Ethics, Springer, v. 50, n. 1, p. 13-31, 2004.

Toward effective codes: Testing the relationship with unethical behavior. Journal of Business Ethics, Springer, v. 99, n. 2, p. 223-251, 2011.

The business codes of the Fortune Global 200. [S.l.]: KPMG, 2014. 
KAPTEIN, M.; SCHWARTZ, M. S. The effectiveness of business codes: A critical examination of existing studies and the development of an integrated research model. Journal of Business Ethics, Springer, v. 77, n. 2, p. 111-127, 2008.

KOWALCZYK-HOYER, B. TRANSPARENCY IN CORPORATE REPORTING. 2014. Disponível em: <https://transparency.eu/wp-content/uploads/2016/10/2014 TransparencyInCorporateReporting_EN.pdf $>$.

LEHNERT, K.; PARK, Y.-h.; SINGH, N. Research note and review of the empirical ethical decision-making literature: Boundary conditions and extensions. Journal of Business Ethics, Springer, v. 129, n. 1, p. 195-219, 2015.

LERE, J. C.; GAUMNITZ, B. R. The impact of codes of ethics on decision making: Some insights from information economics. Journal of Business Ethics, Springer, v. 48, n. 4, p. 365-379, 2003.

LOE, T. W.; FERRELL, L.; MANSFIELD, P. A review of empirical studies assessing ethical decision making in business. Journal of business ethics, Springer, v. 25, n. 3, p. 185-204, 2000.

MAGAZINE, F. Fortune 500. 2017. Disponível em: < https://fortune.com/fortune500/ $2017>$.

NEUENDORF, K. The Content Analysis Guidebook. SAGE Publications, 2016. ISBN 9781483315072. Disponível em: < https://books.google.com.br/books?id= O8yUCwAAQBAJ>.

OUMLIL, A. B.; BALLOUN, J. L. Cultural variations and ethical business decision making: a study of individualistic and collective cultures. Journal of Business \& Industrial Marketing, Emerald Publishing Limited, 2017.

O'FALLON, M. J.; BUTTERFIELD, K. D. A review of the empirical ethical decision-making literature: 1996-2003. Journal of business ethics, Springer, v. 59, n. 4, p. 375-413, 2005.

PAINE, L. S. Managing for organizational integrity. Harvard business review, SUBSCRIBER SERVICE, PO BOX 52623, BOULDER, CO 80322-2623, v. 72, n. 2, p. 106-117, 1994.

SCHKADE, D. A.; KAHNEMAN, D. Does living in california make people happy? a focusing illusion in judgments of life satisfaction. Psychological Science, SAGE Publications Sage CA: Los Angeles, CA, v. 9, n. 5, p. 340-346, 1998.

SCHWARTZ, M. S. Effective corporate codes of ethics: Perceptions of code users. Journal of business ethics, Springer, v. 55, n. 4, p. 321-341, 2004.

Universal moral values for corporate codes of ethics. Journal of Business Ethics, Springer, v. 59, n. 1-2, p. 27-44, 2005.

SECURITIES; COMMISSION, E. Summary by the Division of Corporation Finance of Significant Issues Addressed in the Review of the Periodic Reports of the Fortune $\mathbf{5 0 0}$ Companies. 2003. Disponível em: <https: //www.sec.gov/divisions/corpfin/fortune500rep.htm >. 
SINGH, J. B. A comparison of the contents of the codes of ethics of canada's largest corporations in 1992 and 2003. Journal of Business Ethics, Springer, v. 64, n. 1, p. 17-29, 2006.

SOLTES, E. Why they do it: inside the mind of the white-collar criminal. [S.l.]: PublicAffairs, 2016.

Evaluating the effectiveness of corporate compliance programs: Establishing a model for prosecutors, courts, and firms. NYUJL \& Bus., HeinOnline, v. 14, p. 965, 2017 .

STOHL, C.; STOHL, M.; POPOVA, L. A new generation of corporate codes of ethics. Journal of business ethics, Springer, v. 90, n. 4, p. 607, 2009.

TENBRUNSEL, A. E.; SMITH-CROWE, K.; UMPHRESS, E. E. Building houses on rocks: The role of the ethical infrastructure in organizations. Social justice research, Springer, v. 16, n. 3, p. 285-307, 2003.

THALER, R. H.; GANSER, L. Misbehaving: The making of behavioral economics. [S.l.]: WW Norton New York, 2015.

TREVIÑO, L. K.; WEAVER, G. R.; REYNOLDS, S. J. Behavioral ethics in organizations: A review. Journal of management, Sage Publications Sage CA: Thousand Oaks, CA, v. 32, n. 6, p. 951-990, 2006.

TREVINO, L. K.; YOUNGBLOOD, S. A. Bad apples in bad barrels: A causal analysis of ethical decision-making behavior. Journal of Applied Psychology, American Psychological Association, v. 75, n. 4, p. 378, 1990.

WARREN, R. C. Codes of ethics: bricks without straw. Business Ethics: A European Review, Wiley Online Library, v. 2, n. 4, p. 185-191, 1993.

WEAVER, G. R. Corporate codes of ethics: Purpose, process and content issues.

Business \& Society, Sage Publications Sage CA: Thousand Oaks, CA, v. 32, n. 1, p. 44-58, 1993.

WEAVER, G. R.; TREVIÑO, L. K.; COCHRAN, P. L. Corporate ethics practices in the mid-1990's: An empirical study of the fortune 1000. Journal of Business Ethics, Springer, v. 18, n. 3, p. 283-294, 1999.

WILSON, T. D. et al. Focalism: a source of durability bias in affective forecasting. Journal of personality and social psychology, American Psychological Association, v. 78 , n. 5 , p. 821,2000 .

WOOLDRIDGE, J. M. Introductory econometrics: A modern approach. [S.l.]: Nelson Education, 2015.

ZHANG, T.; GINO, F.; BAZERMAN, M. H. Morality rebooted: Exploring simple fixes to our moral bugs. Research in Organizational Behavior, Elsevier, v. 34, p. 63-79, 2014. 